\title{
Water Resources Planning and Management: An Overview
}

\subsection{Introduction}

Water resource systems have benefited both people and their economies for many centuries. The services provided by such systems are multiple. Yet in many regions of the world they are not able to meet even basic drinking water and sanitation needs. Nor can many of these water resource systems support and maintain resilient biodiverse ecosystems. Typical causes include inappropriate, inadequate and/or degraded infrastructure, excessive withdrawals of river flows, pollution from industrial and agricultural activities, eutrophication resulting from nutrient loadings, salinization from irrigation return flows, infestations of exotic plant and animals, excessive fish harvesting, flood plain and habitat alteration from development activities, and changes in water and sediment flow regimes. The inability of water resource systems to meet the diverse needs for water often reflect failures in planning, management, and decision-makingand at levels broader than water. Planning, developing, and managing water resources to ensure adequate, inexpensive, and sustainable supplies and qualities of water for both humans and natural ecosystems can only succeed if we recognize and address the causal socioeconomic factors, such as inadequate education, corruption, population pressures, and poverty.

Over the centuries, surface and ground waters have been a source of water supply for agricultural, municipal, and industrial consumers. Rivers have provided hydroelectric energy and inexpensive ways of transporting bulk cargo. They have provided people water-based recreational opportunities and have been a source of water for wildlife and their habitats. They have also served as a means of transporting and transforming waste products that are discharged into them. The quantity and quality regimes of streams and rivers have been a major factor in governing the type, health, and biodiversity of riparian and aquatic ecosystems. Floodplains have provided fertile lands for agricultural crop production and relatively flat lands for the siting of roads and railways and commercial and industrial complexes. In addition to the economic benefits that can be derived from rivers and their floodplains, the aesthetic beauty of most natural rivers has made lands adjacent to them attractive sites for residential and recreational development. Rivers and their floodplains have generated, and, if managed properly, can continue to generate, substantial cultural, economic, environmental, and social benefits for their inhabitants.

Human activities undertaken to increase the benefits obtained from rivers and their floodplains may also increase the potential for costs and damages such as when the river is experiencing periods of droughts, floods, and heavy pollution. These costs and damages are physical, economic, environmental, and social. They result because of a mismatch between what humans expect or demand, and what nature offers or supplies. Human activities tend to be based on the "usual or normal" range of river flow conditions. Rare or "extreme" flow conditions 
outside these normal ranges will continue to occur, and possibly with increasing frequency as climate change experts suggest. River-dependent human activities that cannot adjust to these extreme flow conditions will incur losses.

The planning of human activities involving rivers and their floodplains must consider certain hydrologic facts. One of these facts is that surface water flows and aquifer storage volumes vary over space and time. They are also finite. There are limits to the amounts of water that can be withdrawn from them. There are also limits to the amounts of pollutants that can be discharged into them. Once these limits are exceeded, the concentrations of pollutants in these waters may reduce or even eliminate the benefits that could be obtained from other users of the resource.

Water resources professionals have learned how to plan, design, build, and operate structures that together with nonstructural measures increase the benefits people can obtain from the water resources contained in aquifers, lakes, rivers, and estuaries. However, there is a limit to the services one can expect from these resources. Rivers, estuaries, and coastal zones under stress from over development and overuse cannot reliably meet the expectations of those depending on them. How can these resources best be managed and used? How can this be accomplished in an environment of uncertain and varying supplies and uncertain and increasing demands, and consequently of increasing conflicts among individuals having different interests in their management and use? The central purpose of water resources planning, management, and analysis activities is to address, and if possible answer, these questions. These questions have scientific, technical, political (institutional), and social dimensions. Thus water resources planning processes and products are must.

River basin, estuarine, and coastal zone managers - those responsible for managing the resources in those areas - are expected to manage those resources effectively and efficiently, meeting the demands or expectations of all users, and reconciling divergent needs. This is no small task, especially as demands increase, as the variability of hydrologic and hydraulic processes become more pronounced, and as stakeholder expectations of system performance increase in complexity. The focus or goal is no longer simply to maximize economic net benefits while making sure the distribution of those benefits is equitable. There are also environmental and ecological goals to consider. Rarely are management questions one-dimensional, such as how can we provide, at acceptable costs, more high-quality water to municipalities, industry, or to irrigation areas in the basin. Now added to that question is how would those withdrawals affect the downstream hydrologic water quantity and quality regimes, and in turn the riparian and aquatic ecosystems.

Problems and opportunities change over time. Just as the goals of managing and using water change over time, so do the processes of planning to meet these changing goals. Planning processes evolve not only to meet new demands, expectations, and objectives, but also in response to new perceptions of how to plan and manage more effectively.

This chapter reviews some of the issues requiring water resources planning and management. It provides some context and motivation for the following chapters that outline in more detail our understanding of "how to plan" and "how to manage" and how computer-based programs and models can assist those involved in these activities. Additional information is available in many of the references listed at the end of this chapter.

\subsection{Planning and Management Issues: Some Case Studies}

Managing water resources certainly requires knowledge of the relevant physical sciences and technology. But at least as important, if not more so, are the multiple institutional, social, or political issues confronting water resources planners and managers. The following brief descriptions of some water resources planning and management studies at various geographic scales illustrate some of these issues. 


\subsubsection{Kurds Seek Land, Turks Want Water}

The Tigris and Euphrates Rivers (Fig. 1.1) created the "Fertile Crescent" where some of the first civilizations emerged. Today their waters are critical resources, politically as well as geographically. In one of the world's largest public works undertakings, Turkey's Southeast Anatolia Project includes 13 irrigation and hydropower schemes, and the construction of 22 dams and 19 hydroelectric power plants on both the Tigris and the Euphrates. Upon completion, it is expected to provide up to $25 \%$ of the country's electricity.

Its centerpiece, the Ataturk Dam (Fig. 1.2) on the Euphrates River, is already completed. In the lake formed behind the dam, sailing and swimming competitions are being held on a spot where for centuries there was little more than desert (Fig. 1.3).

When the multireservoir project is completed it is expected to increase the amount of irrigated land in Turkey by $40 \%$ and provide up to a quarter of the country's electric power needs. Planners hope this can improve the standard of living of six million of Turkey's poorest people, most of the Kurds, and thus undercut the appeal of revolutionary separatism. It will also reduce the amount of water Syria and Iraq believe they need-water that Turkey fears might ultimately be used in anti-Turkish causes.

The region of Turkey where Kurd's predominate is more or less the same region covered by the Southeast Anatolia Project, encompassing an area about the size of Austria. Giving that region autonomy by placing it under Kurdish self-rule could weaken the central Government's control over the water resource that it recognizes as a keystone of its future power.

In other ways also, Turkish leaders are using their water as a tool of foreign as well as domestic policy. Among their most ambitious projects considered is a 50-mile undersea pipeline to carry water from Turkey to the parched Turkish enclave on northern Cyprus. The pipeline, if actually built, will carry more water than northern Cyprus

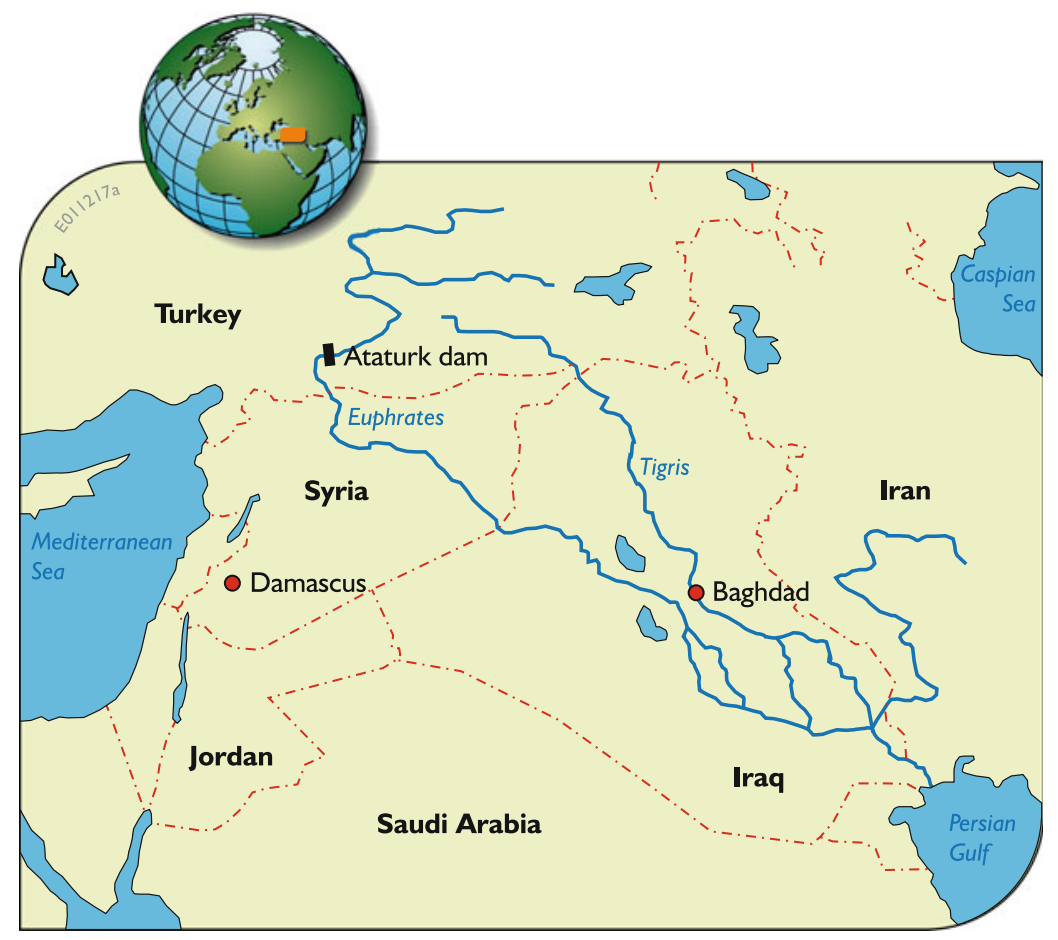

Fig. 1.1 The Tigris and Euphrates Rivers in Turkey, northern Syria, and Iraq 


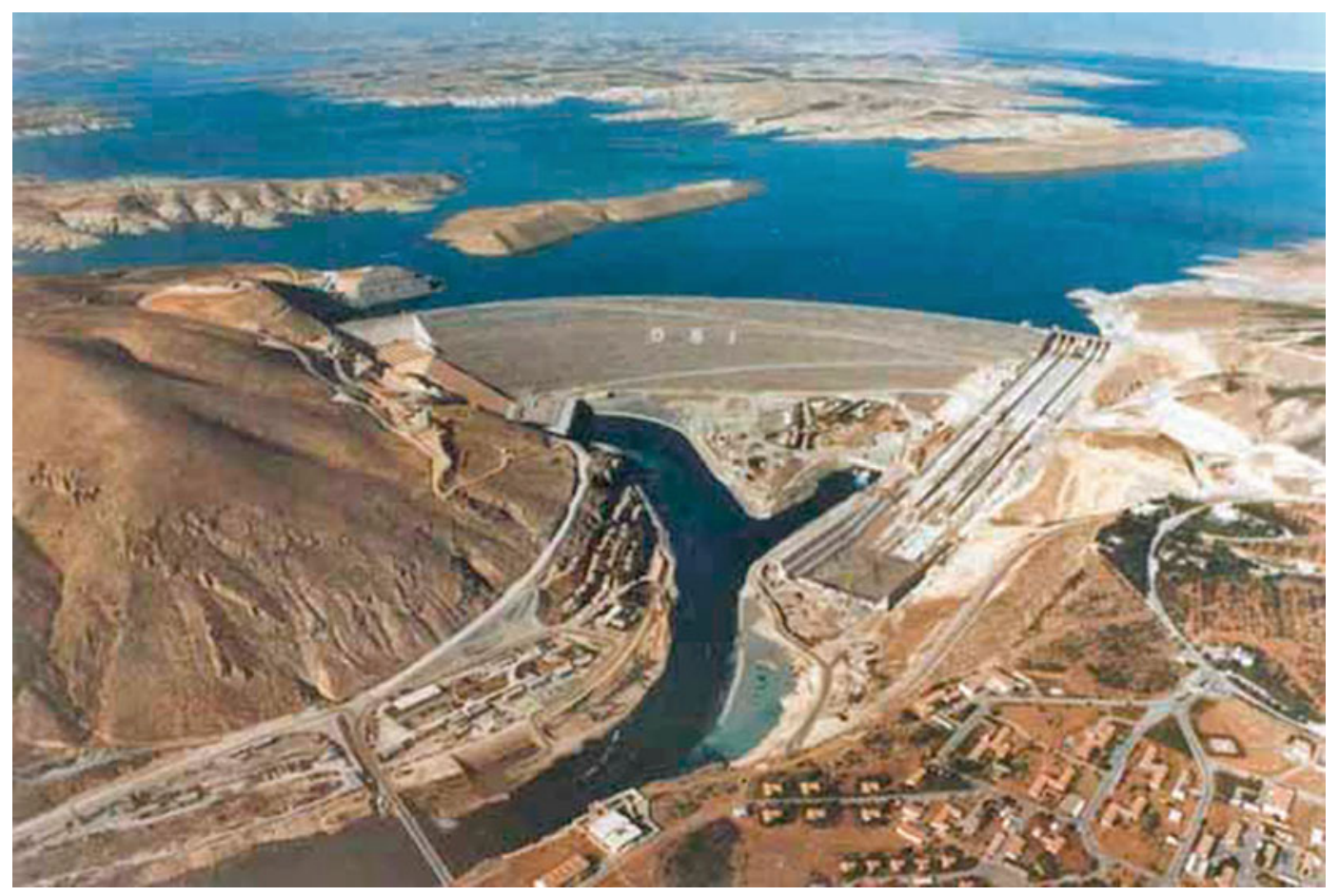

Fig. 1.2 Ataturk Dam on the Euphrates River in Turkey (DSI)

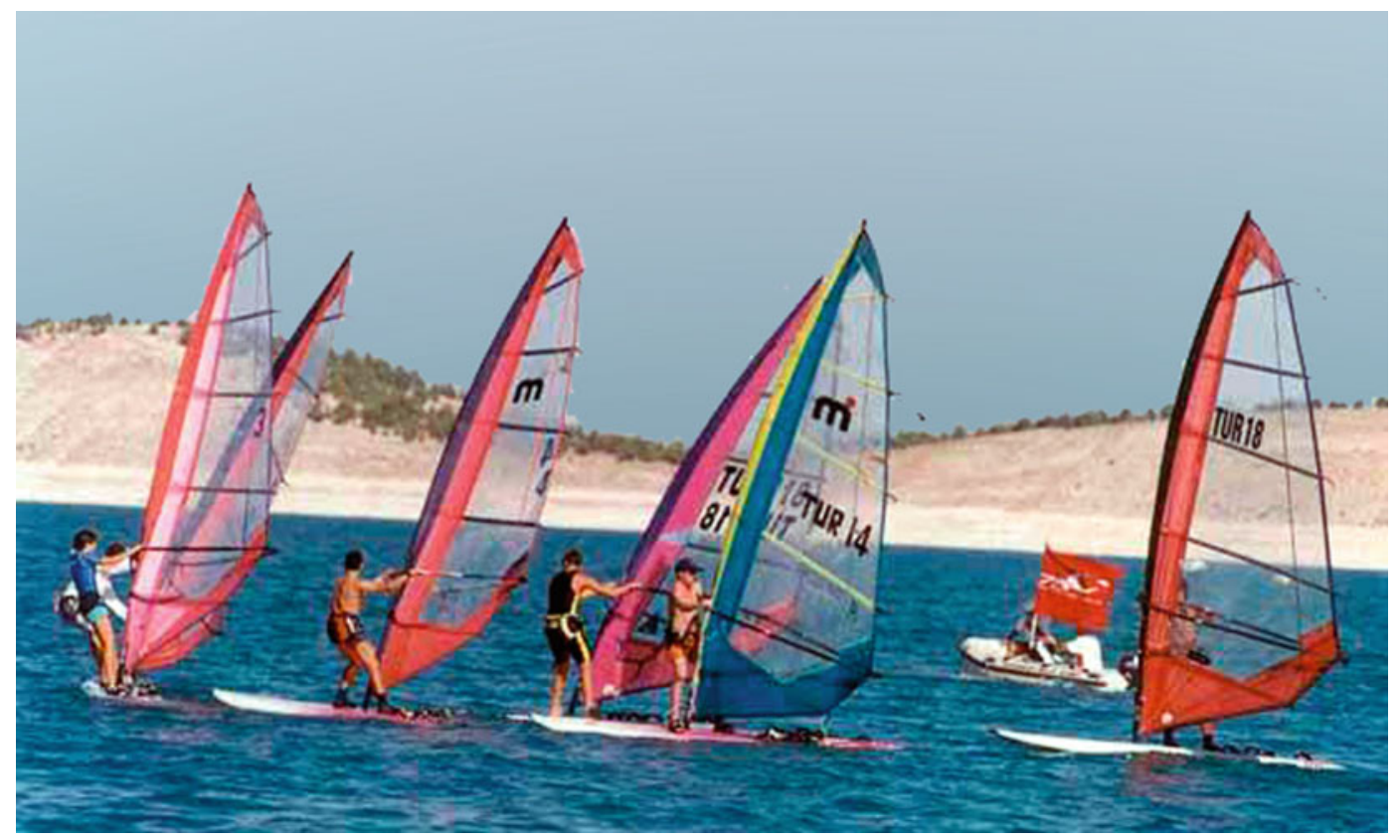

Fig. 1.3 Water sports on Ataturk Reservoir on the Euphrates River in Turkey (DSI) 
can use. Foreign mediators, frustrated by their inability to break the political deadlock on Cyprus, are hoping that the excess water can be sold to the ethnic Greek republic on the southern part of the island as a way of promoting peace.

As everyone knows, the Middle East is currently (2016) witnessing considerable turmoil so who knows the fate of any water resources project in this region, including the one just described in Turkey and the following example in Jordan. One can only hope that the management and use of this scarce resource will lead to more peaceful resolutions of conflicts not only involving water but of other political issues as well.

\subsubsection{Sharing the Water of the Jordan River Basin: Is There a Way?}

A growing population-approximately 12 million people - and intense economic development in the Jordan River Basin (Fig. 1.4) are placing heavy demands on its scarce freshwater resources. This largely arid region receives less than $250 \mathrm{~mm}$ of rainfall each year, yet total water use for agricultural and economic activities has been steadily increasing. This plus encroaching urban development have degraded many sources of high-quality water in the region.

The combined diversions by the riparian water users have changed the river in its lower course into little better than a sewage ditch. From the 1300 million cubic meters $(\mathrm{mcm})$ of water that flowed into the Dead Sea in the 1950s only a small fraction remains at present. In normal years the flow downstream from Lake Tiberias (also called the Sea of Galilee or Lake Kinneret) is some 60 million cubic meters $(\mathrm{mcm})$ - about $10 \%$ of the natural discharge in this section. It mostly consists of saline springs and sewage water. These flows are then joined by what remains of the Yarmouk, by some irrigation return flows, and by winter runoff, adding up to an annual total of from $200-300 \mathrm{mcm}$. Both in quantity and quality this water is unsuitable for irrigation and does not sufficiently supply natural systems either. The salinity of the Jordan River reaches up to 2000 parts per million (ppm) in the lowest section, which renders it unfit for crop irrigation. Only in flood years is fresh water released into the lower Jordan Valley.

One result of this increased pressure on freshwater resources is the deterioration of the region's wetlands. These wetlands are important for water purification and flood and erosion control. As agricultural activities expand, wetlands are being drained, and rivers, aquifers, lakes, and streams are being polluted with runoff containing fertilizers and pesticides. Reversing these trends by preserving natural ecosystems is essential to the future availability of fresh water in the region.

To ensure that an adequate supply of fresh, high-quality water is available for future generations, Israel, Jordan, and the Palestinian Authority will have to work together to preserve aquatic ecosystems (White et al. 1999). Without these natural ecosystems, it will be difficult and expensive to sustain high-quality water supplies. The role of ecosystems in sustaining water supplies has largely been overlooked in the context of the region's water supplies. Vegetation controls storm water runoff and filters polluted water, and it reduces erosion and the amount of sediment that makes its way into water supplies. Streams assimilate wastewater, lakes store clean water, and surface waters provide habitat for many plants and animals.

The Jordan River Basin just like most river basins should be evaluated and managed as a whole system, to permit the comprehensive assessment of the effects of water management options on wetlands, lakes, the lower river, and the Dead Sea coasts. Damage to ecosystems and loss of animal and plant species should be weighed against the potential benefits of developing land and creating new water resources. For example, large river-management projects that divert water to dry areas have promoted intensive year-round farming and urban development, but available river water is declining and becoming increasingly polluted. Attempting to meet current demands solely by withdrawing more ground and surface water could result in widespread environmental degradation and depletion of freshwater resources. 
Fig. 1.4 The Jordan River between Israel and Jordan

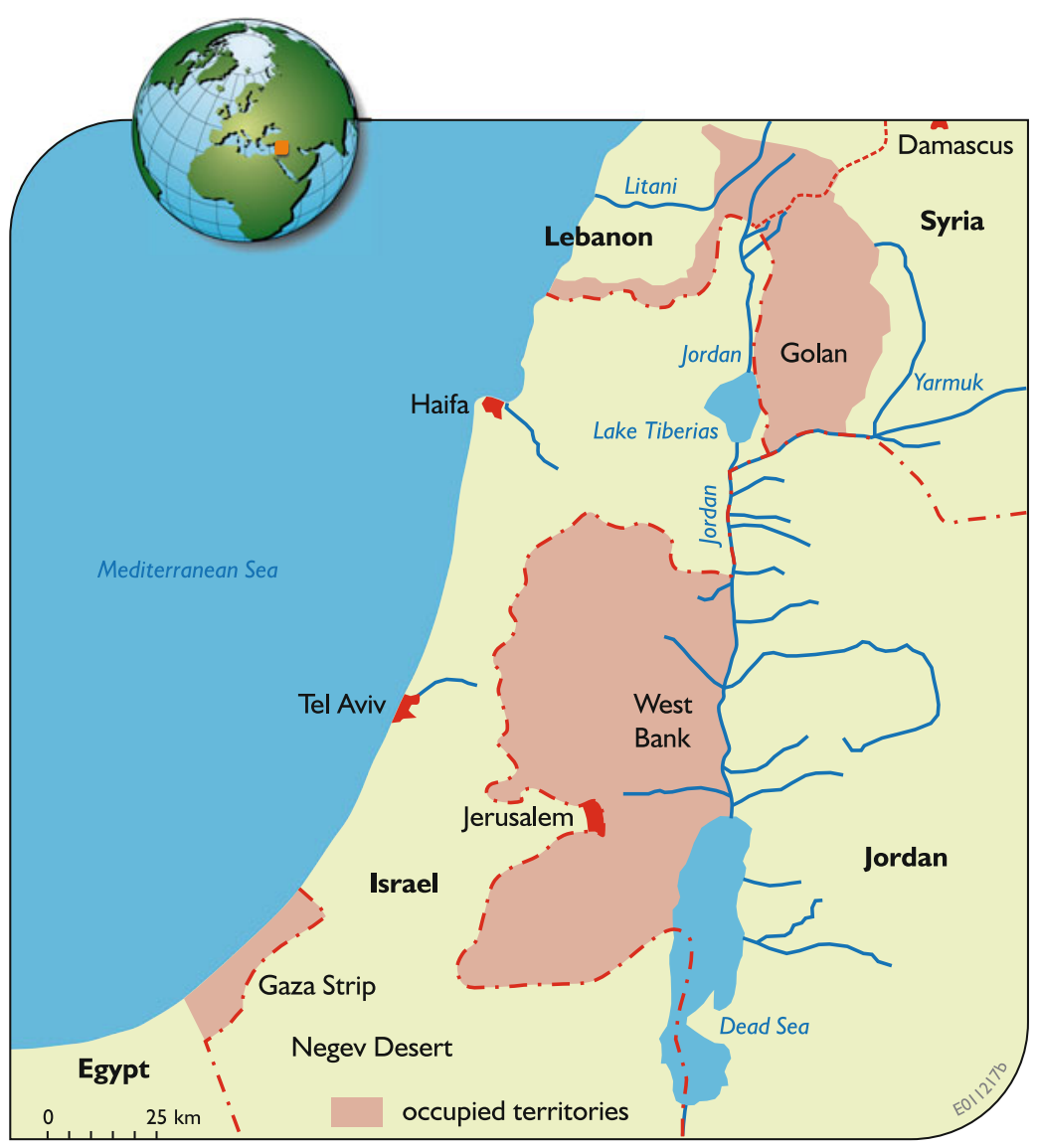

There are policies that if implemented could help preserve the capacity of the Jordan River to meet future demands. Most of the options relate to improving the efficiency of water use - that is, they involve conservation and better use of proven technologies. Also being considered are policies that emphasize economic efficiency and reduce overall water use. Charging higher rates for water use in peak periods, and surcharges for excessive use, would encourage conservation. In addition, new sources of fresh water can be obtained by capturing rainfall through rooftop cisterns, catchment systems, and storage ponds. However before such measures are required, one should assess the impact on local aquifer recharge, storage, and withdrawals.

Thus there are alternatives to a steady deterioration of the water resources of the Jordan Basin. They will require coordination and cooperation among all those living in the basin. Will this be possible?

\subsubsection{Mending the "Mighty and Muddy" Missouri}

Nearly two centuries after an epic expedition through the Western US in search of a northwest river passage to the Pacific Ocean, there is little enchantment left to the Missouri River. Shown in Figs. 1.5 and 1.6, it has been dammed, diked, and dredged since the 1930s mainly to control floods and float cargo barges. The river nicknamed the "Mighty Missouri" and the "Big Muddy" by its explorers is today neither mighty nor muddy. The conservation group American Rivers perennially lists the Missouri among the USA's 10 most endangered rivers. 


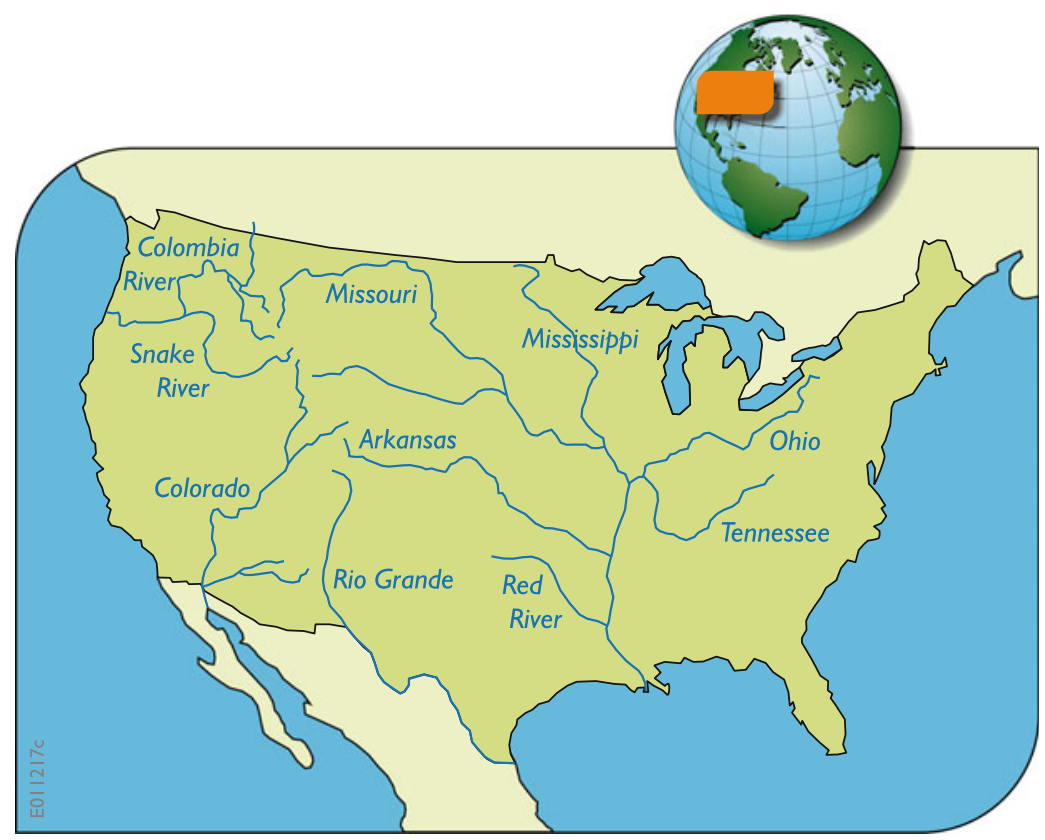

Fig. 1.5 Major river basins in the continental US

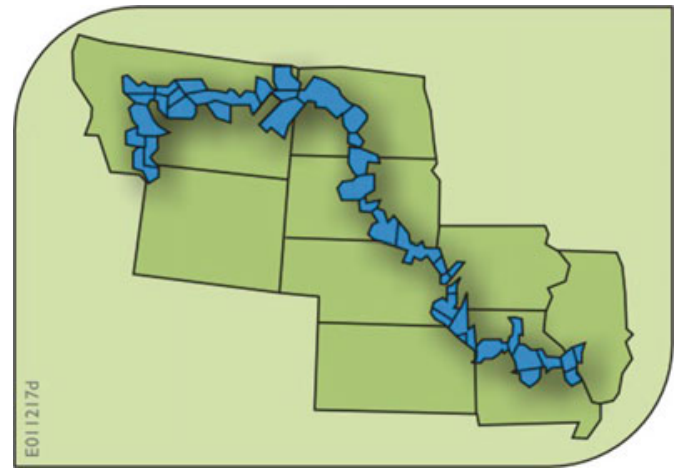

Fig. 1.6 The Missouri Basin's Reservoirs (not to scale) constructed for navigation and flood control

Its wilder upper reaches are losing their cottonwood trees to dam operations and cattle that trample seedlings along the river's banks. Its vast middle contains multiple dams that hold back floods, generate power, and provide pools for boats and anglers.

Its lower one-third is a narrow canal sometimes called "The Ditch" that is deep enough for commercial towboats. Some of the river's banks are armored with rock and concrete retaining walls that protect half a million acres of farm fields from flooding. Once those floods produced and maintained marshlands and side streamshabitats for a wide range of wildlife. Without these habitats, many wild species are unable to thrive, and in some cases even survive.

Changes to restore at least some of the Missouri to a more natural state are being implemented. These changes add protection of fish and wildlife habitat to the list of objectives to be achieved by the government agencies managing the Missouri. The needs of wildlife are now as important as other competing interests on the river including navigation and flood control. This is in reaction, in part, to the booming \$115 million-a-year outdoor recreation industry. Just how much more emphasis will be given to these back-to-nature goals depends on whether the Missouri River Basin Association, an organization representing eight states and 28 Native American tribes, can reach a compromise with the traditional downstream uses of the river. 


\subsubsection{The Endangered Salmon}

Greater Seattle in the northwestern US state of Washington may be best known around the world for Microsoft, but residents know it for something less flashy: its dwindling stock of wild salmon. The Federal Government has placed seven types of salmon and two types of trout on its list of threatened or endangered species. Saving the fish from extinction could slow land development in one of the fastest growing regions of the U.S.

Before the Columbia River and its tributaries in NW US were blocked with dozens of dams, about 10-16 million salmon made the annual run back up to their spawning grounds (Fig. 1.7). In 1996, a little less than 1 million did. But the economy of the NW depends on the dams and locks that have been built in the Columbia that provide cheap hydropower production and navigation.

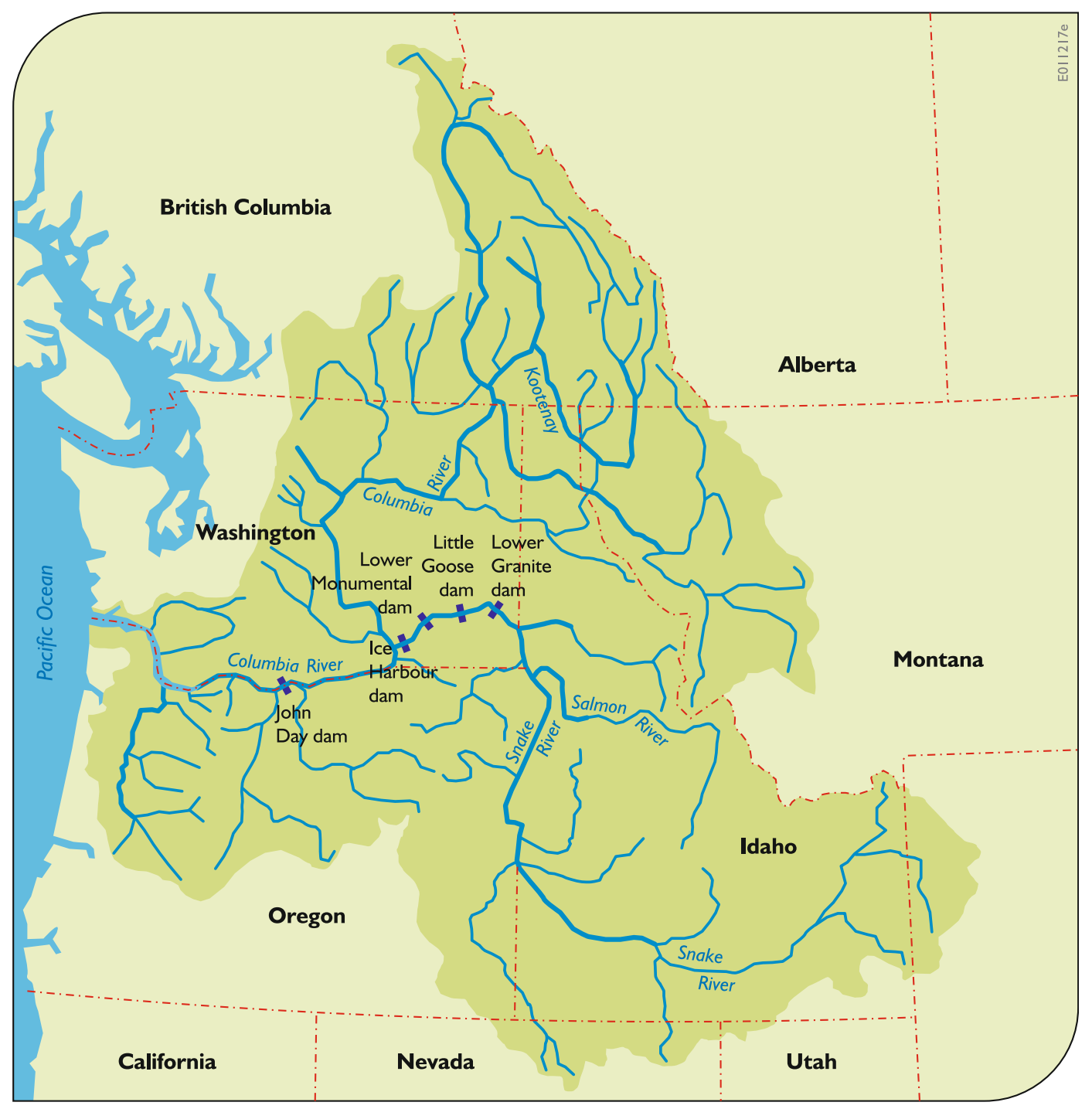

Fig. 1.7 The Snake and Columbia River reservoirs identified by the Columbia and Snake Rivers Campaign for modification or dismantling to permit salmon passage 
For a long time, engineers tried to modify the system so that fish passage would be possible. As shown in Fig. 1.8b, this included even the use of trucks to transport captured juvenile salmon around dams for release downstream. (It is not clear that the trucks will be there when the fish return to spawn upstream of the dams.) These measures have not worked all that well. Still too many young fish enter the hydropower turbines on their way down the river. Now, as the debate over whether or not to remove some dams takes place, fish are caught and trucked around the turbines. The costs of keeping these salmon alive, if not completely happy, are enormous.

Over a dozen national and regional environmental organizations have joined together to bring back salmon and steelhead by modifying or partially dismantling five federal dams on the Columbia and Snake Rivers. Partial removal of the four dams on the lower Snake River in Washington State and lowering the reservoir behind John Day dam on the Columbia bordering
Fig. 1.8 A salmon swimming upstream (a) and measures taken to protect young juvenile salmon pass by hydropower dams on their way downstream (b) (US Fish and Wildlife Service and US Army Corps of Engineers, Pacific region) (a)

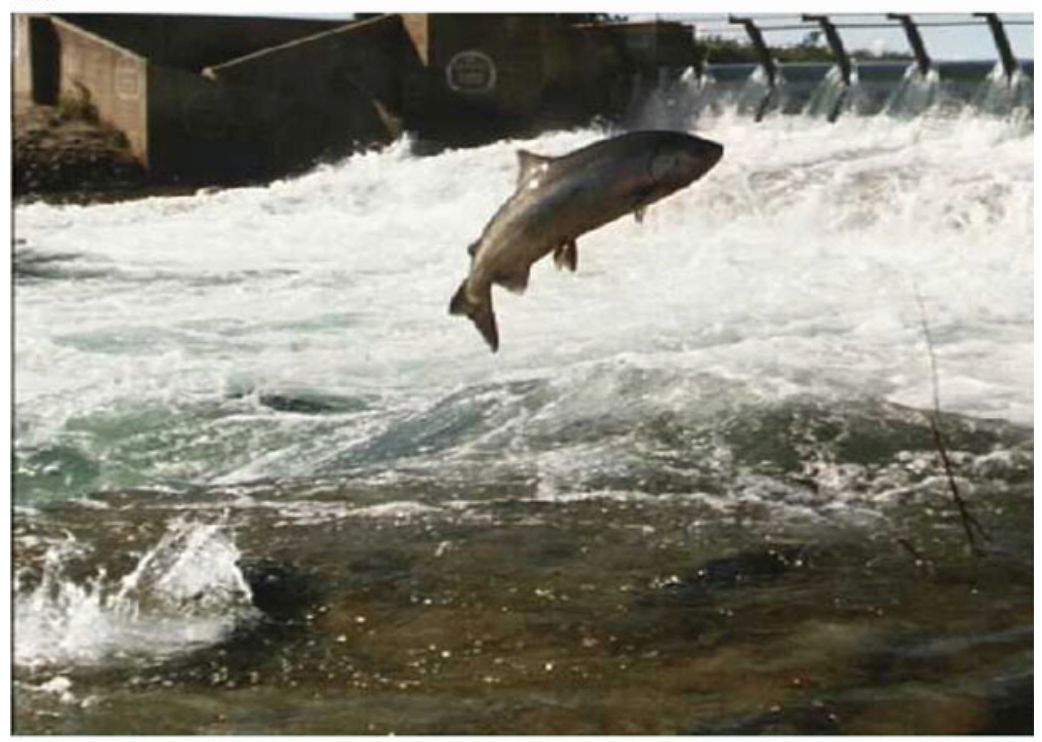

(b)

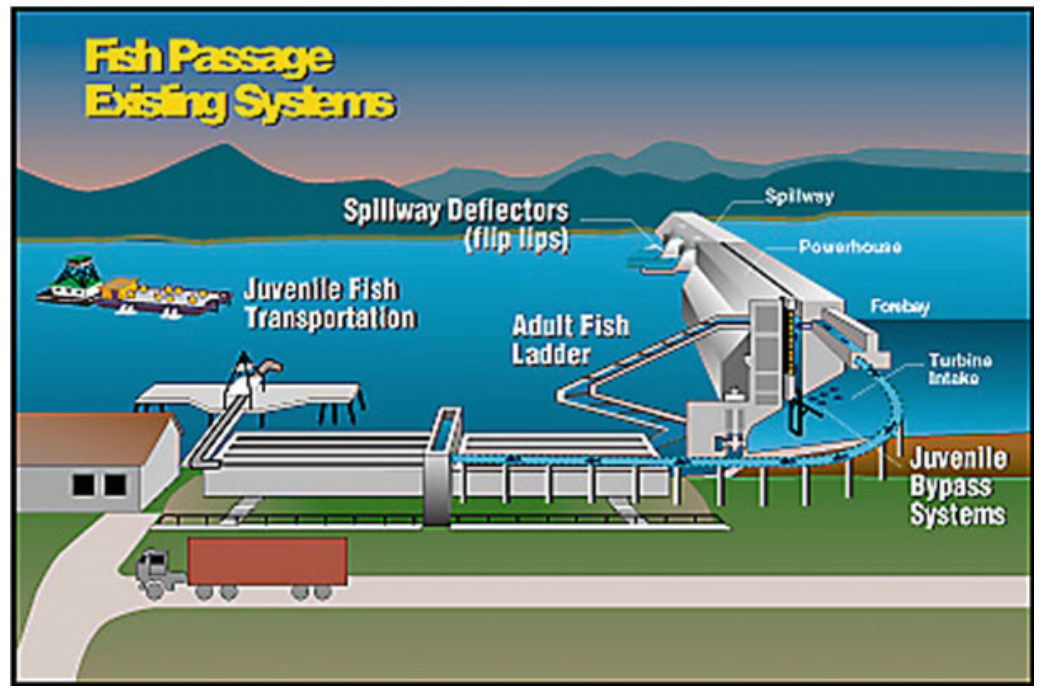


Oregon and Washington (see Fig. 1.8) should help restore over 200 miles of vital river habitat. Running the rivers more like rivers may return salmon and steelhead to harvestable levels of the 1960s before the dams were built.

Dismantling part of the four Lower Snake dams will leave most of each dam whole. Only the dirt bank connecting the dam to the riverbank will be removed. The concrete portion of the dam will remain in place, allowing the river to flow around it. The process is reversible and, the Campaign argues, it will actually save taxpayers money in planned dam maintenance, by eliminating subsidies to shipping industries and agribusinesses, and by ending current salmon recovery measures that are costly. Only partially removing the four Lower Snake River dams and modifying John Day dam will help restore rivers, save salmon, and return balance to the Northwest's major rivers.

\subsubsection{Wetland Preservation: A Groundswell of Support and Criticism}

The balmy beach community of Tiger Point near Pensacola, Florida, bordering the Gulf of Mexico, is booming with development. New subdivisions, a Wal-Mart discount retail store and a recreation center dot the landscape.

Most - if not all — of this neighborhood was once a wetland that soaked up rain during downpours. Now, water runs off the parking lots and the roofs and into resident's living rooms. Some houses get flooded nearly every year.

A federal agency oversees wetland development. Critics say the agency is permitting in this area one of the highest rates of wetland loss in the nation. Obviously local developers wish they did not have to deal with the agency at all. The tension in Tiger Point reflects the debate throughout the US about whether the government is doing enough - or too much - to protect the nation's environment, and in this case, its wetlands.
Environmentalists and some homeowners value wetlands because they help reduce water pollution and floods, as well as nurture a diverse wildlife population. But many landowners and developers see the open wetlands as prime territory for building houses and businesses, rather than for breeding mosquitoes. They view existing federal wetland rules as onerous, illogical, and expensive.

While some areas such as Tiger Point have residents who want stricter laws to limit wetlands development, others-such as the suburbs around Seattle-have people who long for less strict rules.

Federal regulators had tried to quell the controversy with a solution known as wetlands mitigation. Anyone who destroys a wetland is required to build or expand another wetland somewhere else. Landowners and developers also see mitigation as a way out of the torturous arguments over wetlands. However, studies have shown many artificial marshes do not perform as well as those created by nature (NRC 2001). Many of the new, artificial wetlands are what scientists call the "ring around the pond" variety: open water surrounded by cattails. Furthermore, the federal agency issuing permits for wetland replacement do not have the resources to monitor them after they are approved. Developers know this.

\subsubsection{Lake Source Cooling: Aid to Environment, or Threat to Lake?}

It seems to be an environmentalist's dream: a cost-effective system that can cool some 10 million square feet of high school and university buildings simply by pumping cold water from the depths of a nearby lake (Fig. 1.9). No more chlorofluorocarbons, the refrigerants that can destroy protective ozone in the atmosphere and at a cost substantially smaller than for conventional air conditioners. The lake water is returned to the lake, with a few added calories. 


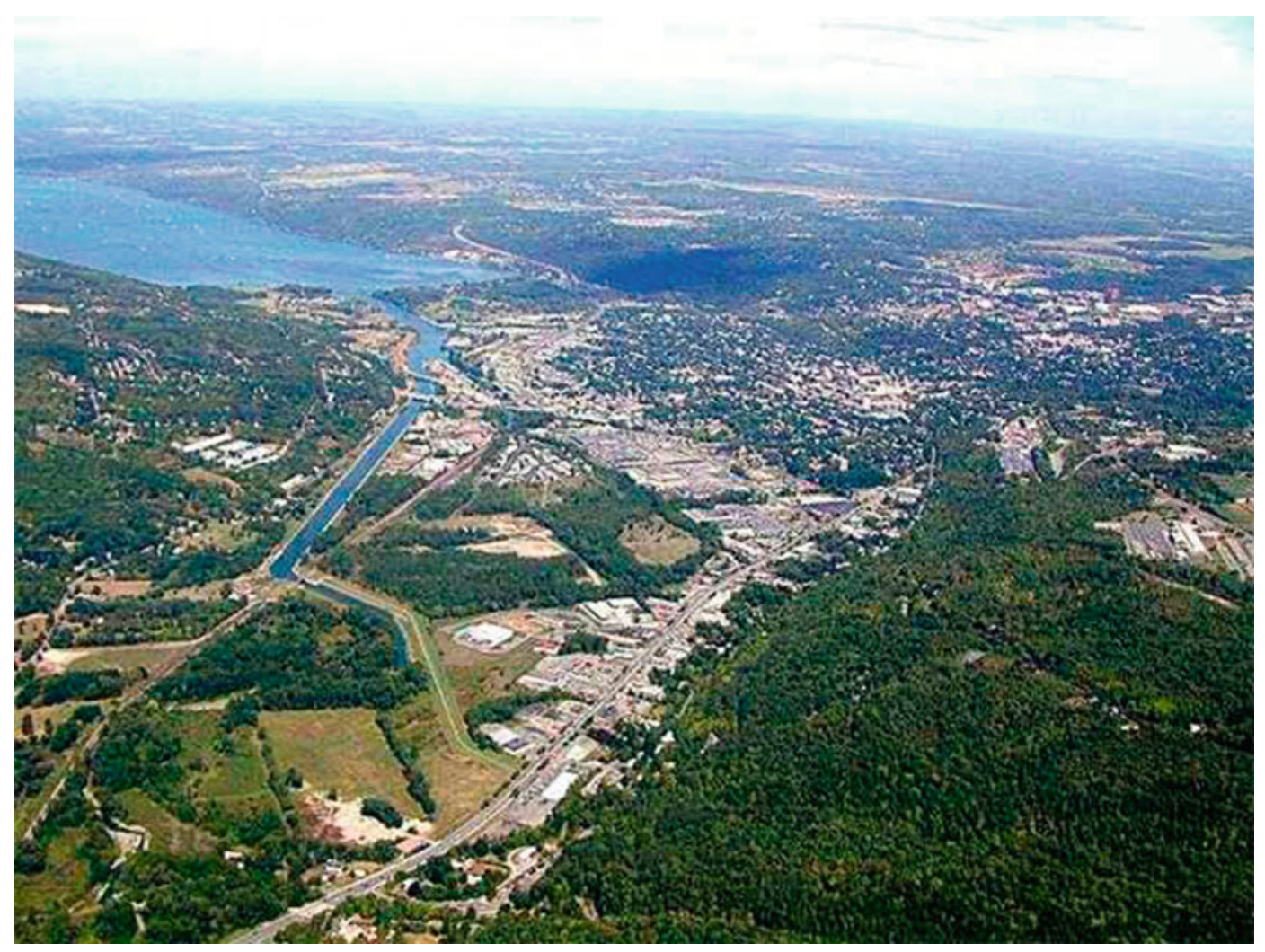

Fig. 1.9 The cold deep waters of Lake Cayuga are being used to cool the buildings of a local school and university (Ithaca City Environmental Laboratory)

However, a group of local opponents insists that Cornell University's \$55 million lake-sourcecooling plan that replaced its aging air conditioners is actually an environmental threat. They believe it could foster algal blooms. Pointing to 5 years of studies, thousands of pages of data, and more than a dozen permits from local and state agencies, Cornell's consultants say the system could actually improve conditions in the lake. Yet another benefit, they say, is that the system would reduce Cornell's contribution to global warming by reducing the need to burn coal to generate electricity.

For the most part, government officials agree. But a small determined coalition of critics from the local community argue over the expected environmental impacts, and over the process that took place in getting the required local, state, and federal permits approved. This is in spite of the fact that the planning process, that took over 5 years, requested and involved the participation of all interested stakeholders (that would participate) from the very beginning. Even the local Sierra Club chapter and biology professors at other universities have endorsed the project. However, in almost every project where the environmental impacts are uncertain, there will be debates among scientists as well as stakeholders. In addition, a significant segment of society distrusts scientists anyway. "This is a major societal problem," wrote a professor and expert in the dynamics of lakes. "A scientist says 
$\mathrm{X}$ and someone else says $\mathrm{Y}$ and you're got chaos. In reality, we are the problem. Every time we flush our toilets, fertilize our lawns, gardens and fields, or wash our cars we contribute to the nutrient loading of the lake."

The project has now been operating for over a decade, and so far no adverse environmental effects have been noticed at any of the many monitoring sites.

\subsubsection{Managing Water in the Florida Everglades}

The Florida Everglades (Fig. 1.10) is the largest single wetland in the continental United States. In the mid-1800s it covered a little over nine million acres, but since that time the historical Everglades has been drained and half of the area devoted to agriculture and urban development. The remaining wetland areas have been altered by human disturbances both around and within them. Water has been diverted for human uses, flows have been lowered to protect against floods, nutrient supplies to the wetlands from runoff from agricultural fields and urban areas have increased, and invasions of nonnative or otherwise uncommon plants and animals have out-competed native species. Populations of wading birds (including some endangered species) have declined by $85-90 \%$ in the last half-century, and many species of South Florida's mammals, birds, reptiles, amphibians, and plants are either threatened or endangered.

The present management system of canals, pumps, and levees (Fig. 1.11) will not be able to provide adequate water supplies to agricultural and urban areas, or sufficient flood protection, let alone support the natural (but damaged) ecosystems in the remaining wetlands. The system is not sustainable. Problems in the greater Everglades ecosystem relate to both water quality and quantity, including the spatial and temporal distribution of water depths, flows, and flooding durations - called hydroperiods. Issues arise because of variations from the natural/historical hydrologic regime, degraded water quality, and the sprawl from fast-growing urban areas.

To meet the needs of the burgeoning population and increasing agricultural demands for water, and to begin the restoration of Everglades' aquatic ecosystem to a more natural regime, an ambitious plan has been developed by the U.S. Army Corps of Engineers and its local sponsor, the South Florida Water Management District. The proposed Corps plan is estimated to cost over $\$ 8$ billion. The plan and its Environmental Impact Statement (EIS) have received input from many government agencies and nongovernmental organizations, as well as from the public at large.

The plan to restore the Everglades is ambitious and comprehensive, involving change of the current hydrologic regime in the remnant Everglades to one that resembles a more natural one, reestablishment of marshes and wetlands, implementation of agricultural best management practices, enhancements for wildlife and recreation, and provisions for water supply and flood control.

Planning for and implementing the restoration effort requires application of state-of-the-art large systems analysis concepts, hydrological and hydroecological data and models incorporated within decision support systems, integration of social sciences, and monitoring for planning and evaluation of performance in an adaptive management context. These large, complex challenges of the greater Everglades restoration effort demand the most advanced, interdisciplinary, and scientifically sound analysis capabilities that are available. They also require the political will to make compromises and to put up with the lawsuits by anyone possibly disadvantaged by some restoration measure.

Who pays for all this? The taxpayers of Florida and the taxpayers of the U.S. 
Fig. 1.10 Scenes of the Everglades in southern Florida (South Florida Water Management District)
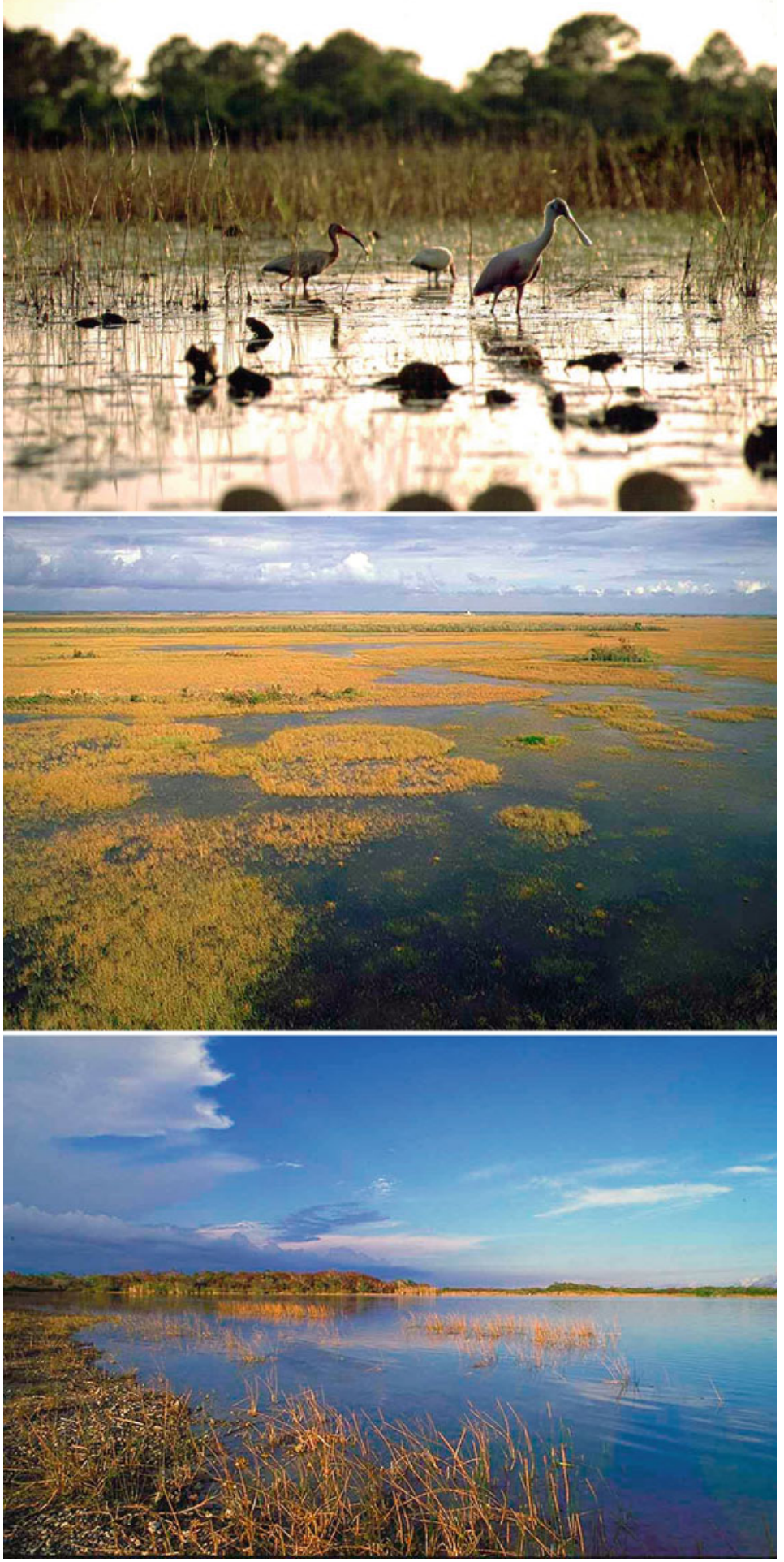


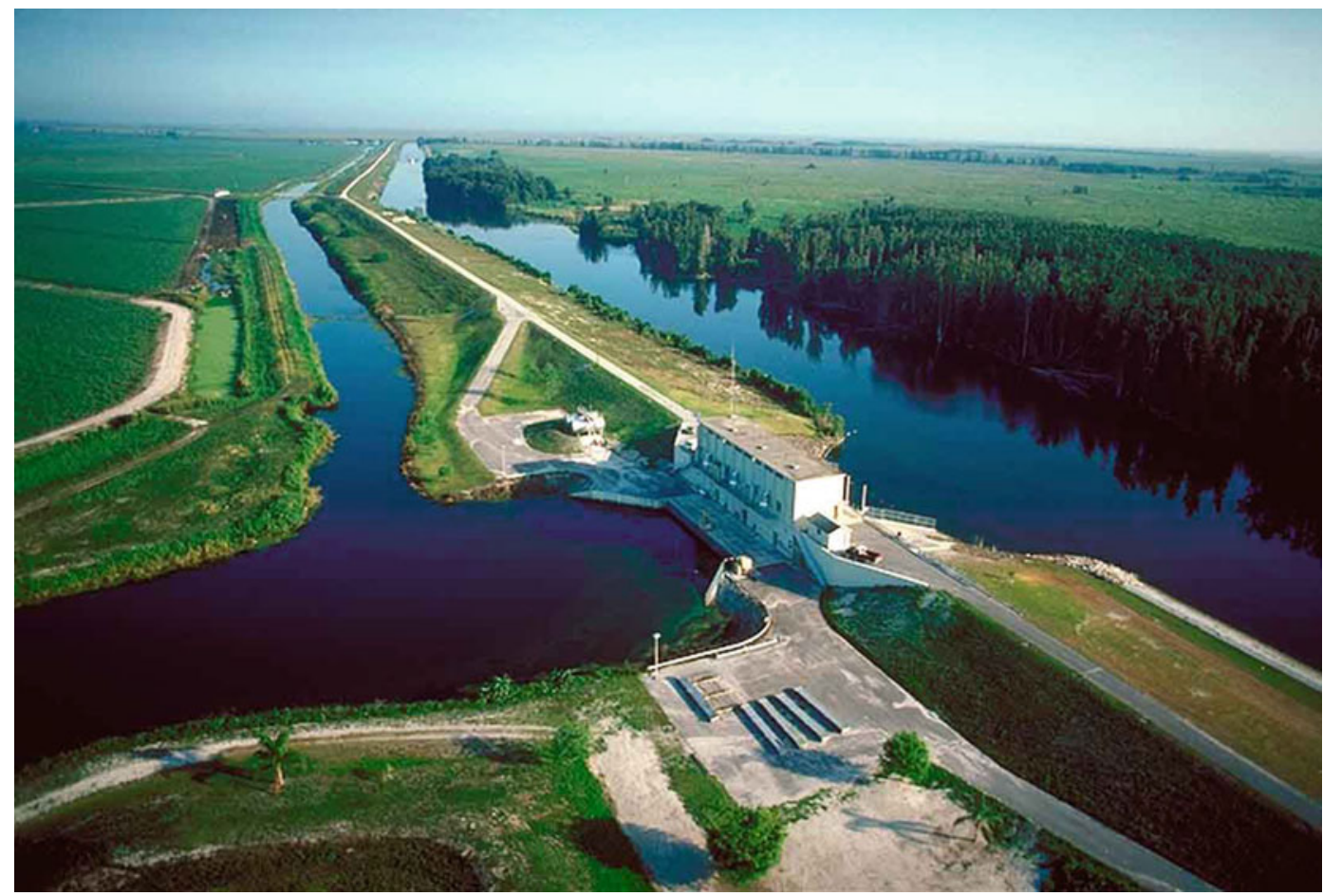

Fig. 1.11 Pump station on a drainage canal in southern Florida (South Florida Water Management District)

\subsubsection{Restoration of Europe's Rivers and Seas}

\subsubsection{North and Baltic Seas}

The North and Baltic Seas (shown in Fig. 1.12) are the most densely navigated seas in the world. Besides shipping, military, and recreational uses, an offshore oil industry and telephone cables cover the seabed. The seas are rich and productive with resources that include not only fish but also crucial minerals (in addition to oil) such as gas, sand, and gravel. These resources and activities play major roles in the economies of the surrounding countries.

Being so intensively used and surrounded by advanced industrialized countries, pollution problems are serious. The main pollution sources include various wastewater outfalls, dumping by ships (of dredged materials, sewage sludge, and chemical wastes) and operational discharges from offshore installations. Deposition of atmospheric pollutants is an additional major source of pollution.
Those parts of the seas at greatest risk from pollution are where the sediments come to rest, where the water replacement is slowest and where nutrient concentrations and biological productivity are highest. A number of warning signals have occurred.

Algal populations have changed in number and species. There have been algal blooms, caused by excessive nutrient discharge from land and atmospheric sources. Species changes show a tendency toward more short-lived species of the opportunistic type and a reduction, sometimes to the point of disappearance, of some mammals and fish species and the sea grass community. Decreases of ray, mackerel, sand eel, and echinoderms due to eutrophication have resulted in reduced plaice, cod, haddock and dab, mollusk and scoter.

The impact of fishing activities is also considerable. Sea mammals, sea birds, and Baltic fish species have been particularly affected by the widespread release of toxins and pollutants accumulate in the sediments and in the food web. 


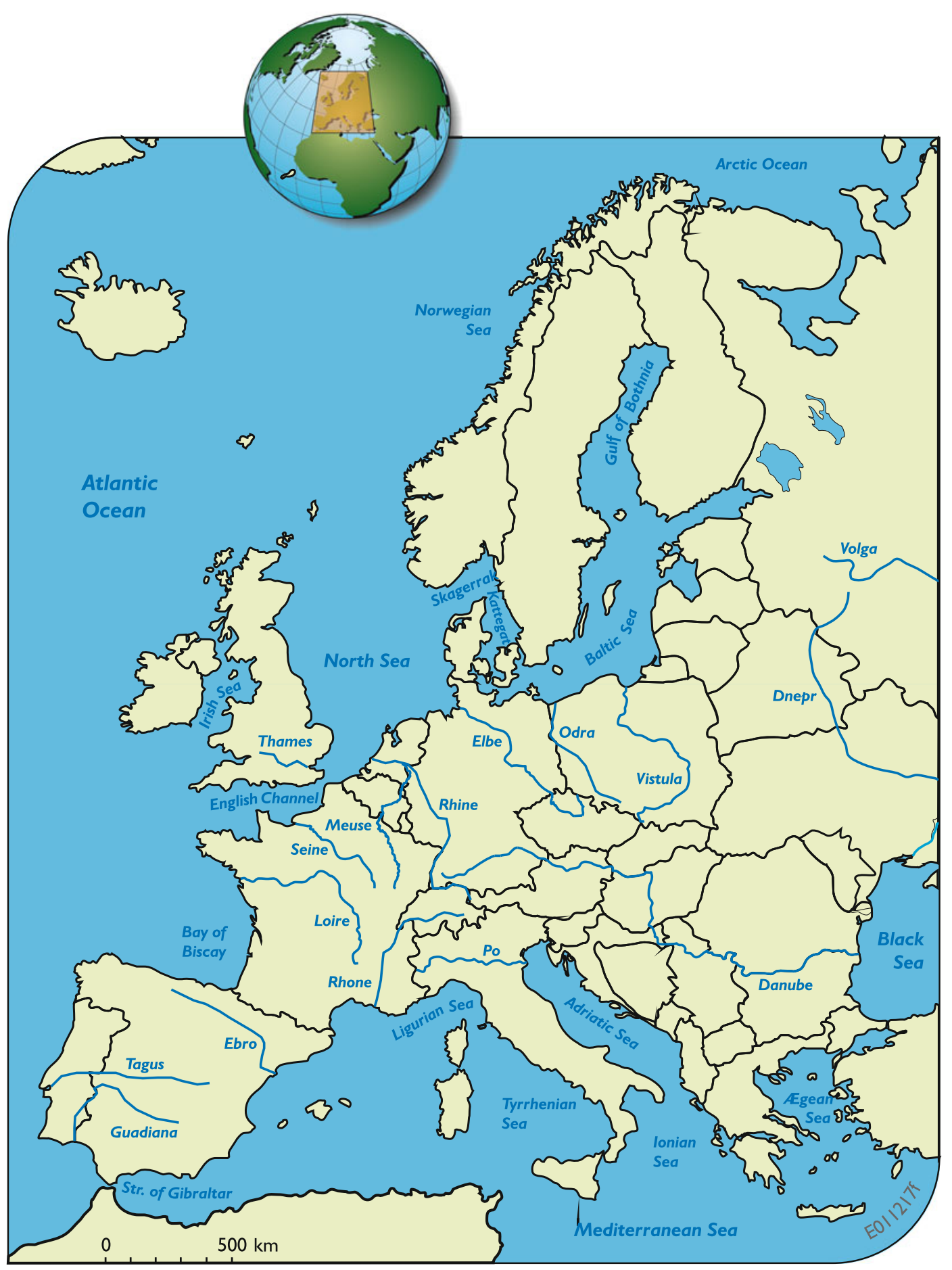

Fig. 1.12 Europe's major rivers and seas 
Some animals, such as the gray seal and the sea eagle, are threatened with extinction.

Particular concern has been expressed about the Wadden Sea that serves as a nursery for many North Sea species. Toxic PCB contamination, for example, almost caused the disappearance of seals in the 1970s. Also, the 1988 massive seal mortality in the North and Wadden Seas, although caused by a viral disease, is still thought by many to have a link with marine pollution.

Although the North Sea needs radical and lengthy treatment it is probably not a terminal case. Actions are being taken by bordering countries to reduce the discharge of wastes into the sea. A major factor leading to agreements to reduce discharges of wastewaters has been the verification of predictive pollutant circulation models of the sea that identify the impacts of discharges from various sites along the sea boundary.

\subsubsection{The Rhine}

The map of Fig. 1.13 shows the areas of the nine countries that are part of river Rhine basin. In the Dutch area of the Rhine basin, water is partly routed northward through the IJssel and westward through the highly interconnected river systems of the Rhine, Meuse, and Waal.

About 55 million people live in the Rhine River basin and about 20 million of those people drink the river water.

In the mid 1970s, some called the Rhine the most romantic sewer in Europe. In November 1986, a chemical spill degraded much of the upper Rhine's aquatic ecosystem. This damaging event was reported worldwide. The Rhine was again world news in the first 2 months of 1995, when its water level reached a height that occurs on average once in a century. In the Netherlands, some 200,000 people, $1,400,000$ pigs and cows, and 1,000,000 chickens had to be evacuated. During the last 2 months of the same year there was hardly enough water in the Rhine for navigation. It is fair to say these events have focused increased attention on what needs to be done to "restore" and protect the Rhine.

To address just how to restore the Rhine, it is useful to look at what has been happening to the river during the past 150 years. The Rhine was originally a natural watercourse. It is the only river connecting the Alps with the North Sea. To achieve greater economic benefits from the river, it was engineered for navigation, hydropower, water supply, and flood protection. Flood plains now "protected" from floods, provided increased land areas suitable for development. The main stream of the Rhine is now considerably shorter and narrower and deeper than it was originally.

From an economic development point of view, the engineering works implemented in the river and its basin worked. The Rhine basin is now one of the most industrialized regions in the world. The basin is characterized by intensive industrial and agricultural activities. Some $20 \%$ of the world's chemical industry is located in the Rhine River basin. The River is reportedly the busiest shipping waterway in the world, containing long canals with regulated water levels. These canals connect the Rhine and its tributaries with the rivers of almost all the surrounding river basins including the Danube River. This provides water transport to and from the North and Black Seas.

From an environmental and ecological viewpoint, and from the viewpoint of flood control as well, the economic development that has taken place over the past two centuries has not worked perfectly. The concerns growing from the recent toxic spill and floods as from a generally increasing interest by the inhabitants of the basin in environmental and ecosystem restoration and the preservation of natural beauty, has resulted in basin-wide efforts to rehabilitate the basin to a more "living" sustainable entity.

A Rhine Action Programme was created to revive the ecosystem. The goal of that program is the revival of the main stream as the backbone of the ecosystem, particularly for migratory fish, and the protection, maintenance, and the revival of ecologically important areas along the Rhine. The plan, implemented in the 1990s, was given the name "Salmon 2000". The return of salmon to the Rhine is seen as a symbol of ecological revival. A healthy salmon population will need to swim throughout the river length. This will pose a challenge, as no one pretends that the 


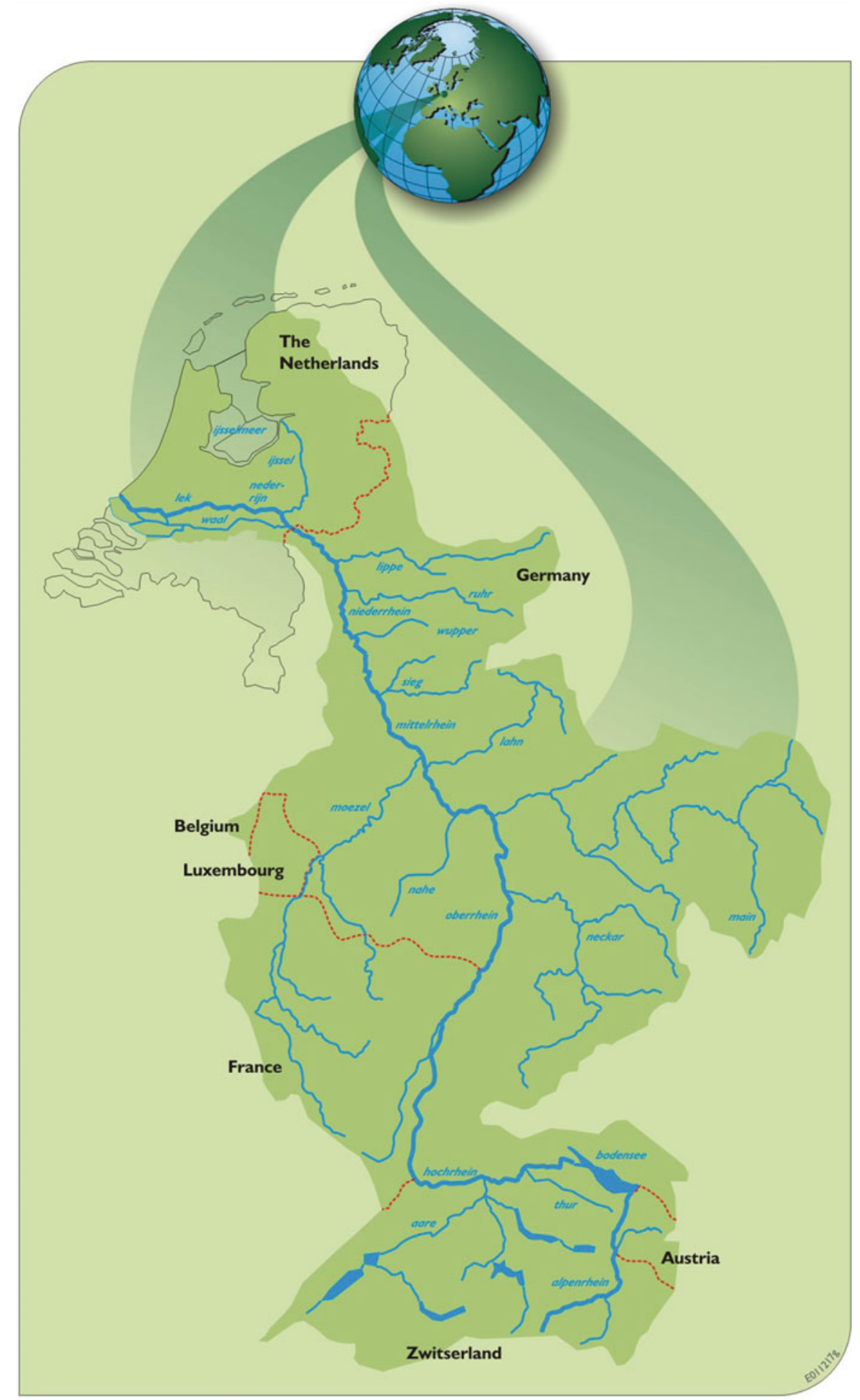

Fig. 1.13 The Rhine River Basin of Western Europe and its extension in The Netherlands 
engineering works that provide navigation and hydropower benefits, but which also inhibit fish passage, are no longer needed or desired.

\subsubsection{The Danube}

The Danube River (shown in Fig. 1.14) is in the heartland of Central Europe. Its basin includes to a larger extent the territories of 15 countries. It additionally receives runoff from small catchments located in four other countries. About 90 million people live in the basin. This river encompasses perhaps more political, economic, and social variations than arguably any other river basin in Europe.

The river discharges into the Black Sea. The Danube delta and the banks of the Black Sea have been designated a Biosphere Reserve by UNESCO. Over half of the Delta has been declared a "wet zone of international significance." Throughout its length the Danube River provides a vital resource for drainage, communications, transport, power generation, fishing, recreation, and tourism. It is considered to be an ecosystem with irreplaceable environmental values.

More than 40 dams and large barrages plus over 500 smaller reservoirs have been constructed on the main Danube River and its tributaries. Flood control dikes confine most of the length of the main stem of the Danube River and the major tributaries. Over the last 50 years natural alluvial flood plain areas have declined from about $26,000 \mathrm{~km}^{2}$ to about $6000 \mathrm{~km}^{2}$.

There are also significant reaches with river training works and river diversion structures. These structures trap nutrients and sediment in the reservoirs. This causes changes in downstream flow and sediment transport regimes that reduce the ecosystems' habitats both longitudinally and transversely, and decrease the efficiency of natural purification processes. Thus while these engineered facilities provide important opportunities for the control and use of the river's resources, they also illustrate the

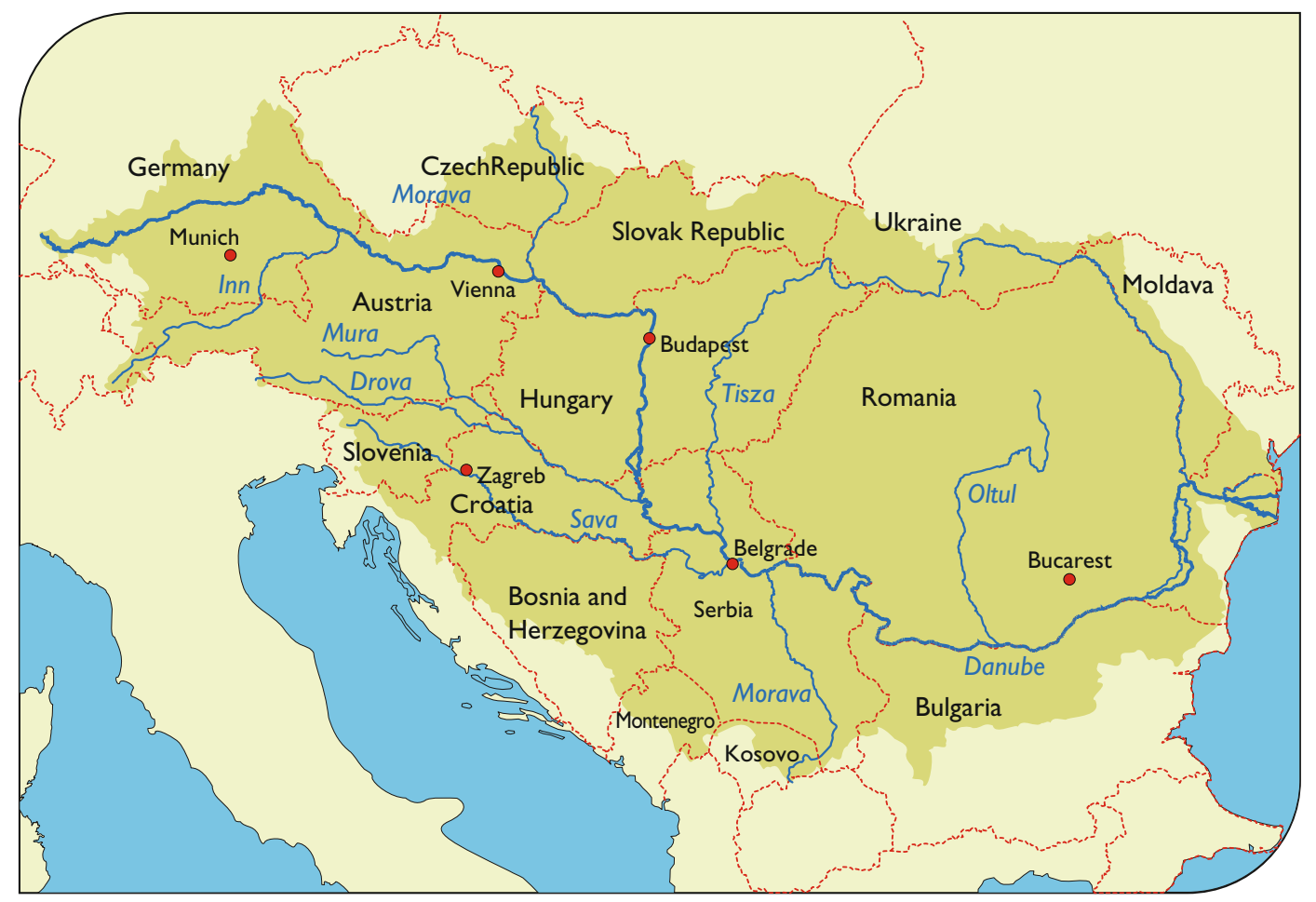

Fig. 1.14 The Danube River in Central Europe 
difficulties of balancing these important economic activities with environmentally sound and sustainable management.

The environmental quality of the Danube River is also under intense pressure from a diverse range of human activities, including point source and nonpoint source agricultural, industrial, and municipal wastes. Because of the poor water quality (sometimes affecting human health) the riparian countries of the Danube river basin have been participating in environmental management activities on regional, national, and local levels for several decades. All Danube countries signed a formal Convention on Cooperation for the Protection and Sustainable Use of the Danube River in June 1994. The countries have agreed to take “... all appropriate legal, administrative and technical measures to improve the current environmental and water quality conditions of the Danube River and of the waters in its catchment area and to prevent and reduce as far as possible adverse impacts and changes occurring or likely to be caused."

\subsubsection{Flood Management on the Senegal River}

As on many rivers in the tropical developing world, dam constructions on the Senegal (and conventional dam management strategies) can change not only the riverine environment but also the social interactions and economic productivity of farmers, fishers, and herders whose livelihoods depend on the annual flooding of valley bottomlands. Although much of the Senegal River flows through a low rainfall area, the naturally occurring annual flooding supported a rich and biologically diverse ecosystem. Living in a sustainable relationship with their environment, small-land holders farmed sandy uplands during the brief rainy season, and then cultivated the clay plains as floodwaters receded to the main channel of the river. Livestock also benefited from the succession of rain-fed pastures on the uplands and flood-recession pastures on the plains. Fish were abundant. As many as 30,000 tons were caught yearly. Since the early 1970 s, small irrigated rice schemes added a fifth element to the production array: rain-fed farming, recession farming, herding, fishing, and irrigation.

Completion of the Diama salt intrusion barrage near the mouth of the river between Senegal and Mauritania and Manantali High Dam more than $1000 \mathrm{~km}$ upstream in Mali (Fig. 1.15), and the termination of the annual flood have had adverse effects on the environment. Rather than insulating the people from the ravages of drought, the dam release policy can accelerate desertification and intensify food insecurity. Furthermore, anticipation of donor investments in huge irrigation schemes has, in this particular case, lead to the expulsion of non-Arabic-speaking black Mauritanians from their floodplain lands.
Fig. 1.15 Senegal River and its Manantali Reservoir more than $1000 \mathrm{~km}$ upstream in Mali

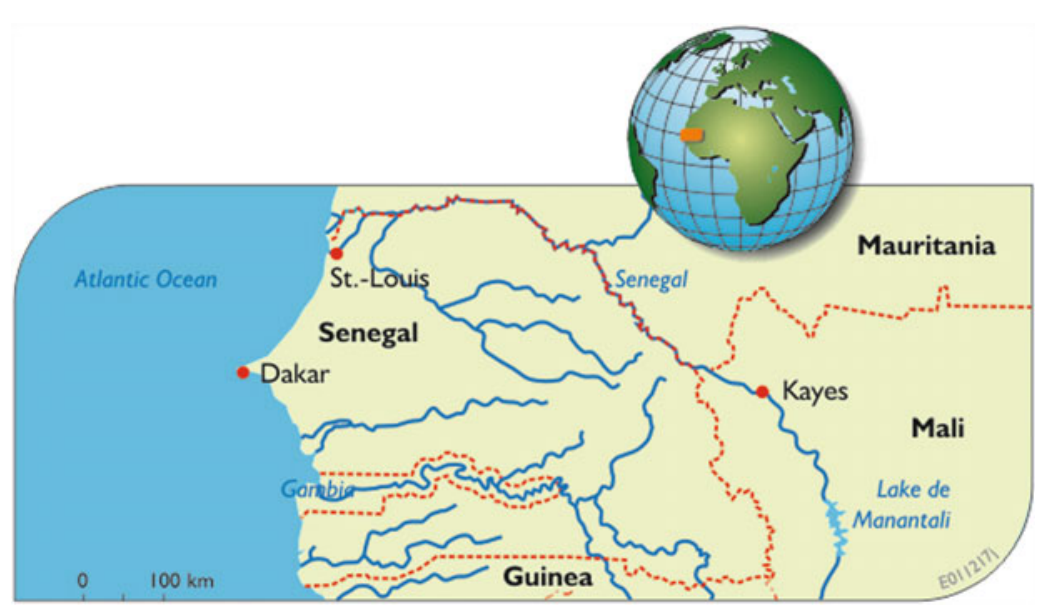


This is a common impact of dam construction: increased hardships of generally politically powerless people in order that urban and industrial sectors may enjoy electricity at reduced costs.

Studies in the Senegal Valley by anthropologists, hydrologists, agronomists, and others suggest that it may be entirely economically feasible to create a controlled annual "artificial flood," assuring satisfaction of both urban, industrial, and rural demands for the river's water and supporting groundwater recharge, reforestation, and biodiversity.

Because of these studies, the government of Senegal ended its opposition to an artificial flood, and its development plans for the region are now predicated on its permanence. However, due to the common belief that releasing large quantities of water to create an artificial flood is incompatible with maximum hydropower production, the other members of the three-country consortium managing the dams - Mali and Mauritania - have resisted accepting this policy.

\subsubsection{Nile Basin Countries Striving to Share Its Benefits}

The Nile River (Fig. 1.16) is one of the major rivers of the world, serving millions and giving birth to entire civilizations. It is one of the world's longest rivers, traversing about $6695 \mathrm{~km}$ from the farthest source of its headwaters in Rwanda and Burundi through Lake Victoria, to its delta in Egypt on the Mediterranean Sea. Its basin includes 11 African countries (Burundi, DR Congo, Egypt, Eritrea, Ethiopia, Kenya, Rwanda, South Sudan, The Sudan, and Tanzania) and extends for more than 3 million square kilometers which represents about $10 \%$ of Africa's land mass area. The basin includes the Sudd wetland system in South Sudan.

Nile Basin countries are today home to more than 437 million people and of these, $54 \%$ (238 million) live within the basin and expect benefits from the management and use of the shared Nile Basin water resources.
Notwithstanding the basin's natural and environmental endowments and rich cultural history, its people face considerable challenges including persistent poverty with millions living on less than a dollar a day; extreme weather events associated with climate variability and change such as floods and droughts; low access to water and sanitation services; deteriorating water quality; and very low access rate to modern energy with most countries below 20\% access level. The region also has a history of tensions and instability both between states and internal to states.

Cooperative management and development could bring a vast range of benefits including increased hydropower and food production; better access to water for domestic use; improved management of watersheds and reduced environmental degradation; reduced pollution and more control over damage from floods and droughts. Recognizing this the Nile Basin Initiative was created as a regional intergovernmental partnership that seeks to develop the River Nile in a cooperative manner, share substantial socioeconomic benefits, and promote regional peace and security. The partnership includes 10 Member States namely Burundi, DR Congo, Egypt, Ethiopia, Kenya, Rwanda, South Sudan, The Sudan, Tanzania, and Uganda. Eritrea participates as an observer. NBI was conceived as a transitional institution until a permanent institution can be created.

The partnership is guided by a Shared Vision: "To achieve sustainable socio-economic development through equitable utilization of, and benefit from, the common Nile Basin Water resources." The shared belief is that countries can achieve better outcomes for all the peoples of the Basin through cooperation rather than competition. It is supported by a "Shared Vision Planning Model" built by experts from all the basin countries. The model is designed to run different scenarios and assess the basin-wide impacts of different management policies and assumptions that any country may wish to perform. 


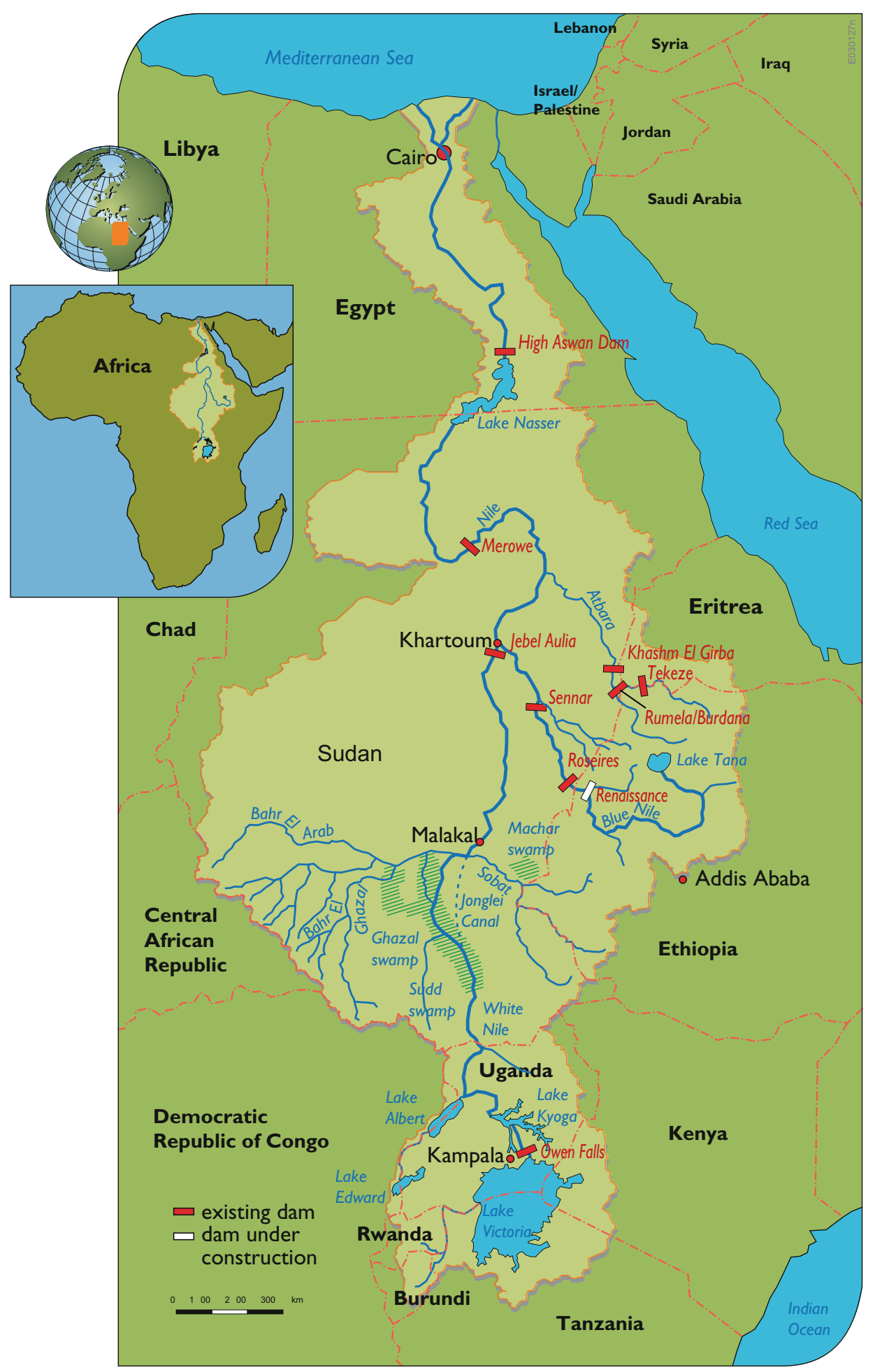

Fig. 1.16 The Nile River Basin 


\subsubsection{Shrinking Glaciers at Top of the World}

As shown in Fig. 1.17, Tibet lies north of India, Nepal, Bhutan, and Myanmar, west of China, and south of East Turkistan. The highest and largest plateau on Earth, it stretches some 1500 miles $(2400 \mathrm{~km})$ from east to west, and 900 miles $(1448 \mathrm{~km})$ north to south, an area equivalent in size to the United States region east of the Mississippi River. The Himalayas form much of its southern boundary, and Tibet's average altitude is so high $-11,000$ feet $(3350 \mathrm{~km})$ above sea level - that visitors often need weeks to acclimate.

The Tibetan Plateau serves as the headwaters for many of Asia's largest rivers, including the Yellow, Yangtze, Mekong, Brahmaputra, Salween, and Sutlej, among others. A substantial portion of the world's population lives in the watersheds of the rivers whose sources lie on the Tibetan Plateau.

Recent studies-including several by the Chinese Academy of Sciences-have documented a host of serious environmental challenges involving the quantity and quality of Tibet's freshwater reserves, most of them caused by industrial activities. Deforestation has led to large-scale erosion and siltation. Mining, manufacturing, and other human and industrial activities are producing record levels of air and water pollution in Tibet, as well as elsewhere in China
(Wong 2013). Together, these factors portend future water scarcity that could add to the region's political volatility.

Most important is that the region's glaciers are receding at one of the fastest rates anywhere in the world, and in some regions of Tibet by three $3 \mathrm{~m}$ per year (IPPC 2007). The quickening melting and evaporation is raising serious concerns in scientific and diplomatic communities, in and outside China, about Tibet's historic capacity to store more freshwater than anyplace on earth, except the North and South Poles. Tibet's water resources, they say, have become an increasingly crucial strategic political and cultural element that the Chinese are intent on managing and controlling.

\subsubsection{China, a Thirsty Nation}

Why does China care about the freshwater in Tibet? With more than a quarter of its land classified as desert, China is one of the planet's most arid regions. Beijing is besieged each spring by raging dust storms born in Inner Mongolia where hundreds of square miles of grasslands are turning to desert each year. In other parts of the nation, say diplomats and economic development specialists, Chinese rivers are either too polluted or too filled with silt to provide all of China's people with adequate supplies of freshwater.
Fig. 1.17 China, India, and Southeast Asia, highlighting the Tibetan Plateau

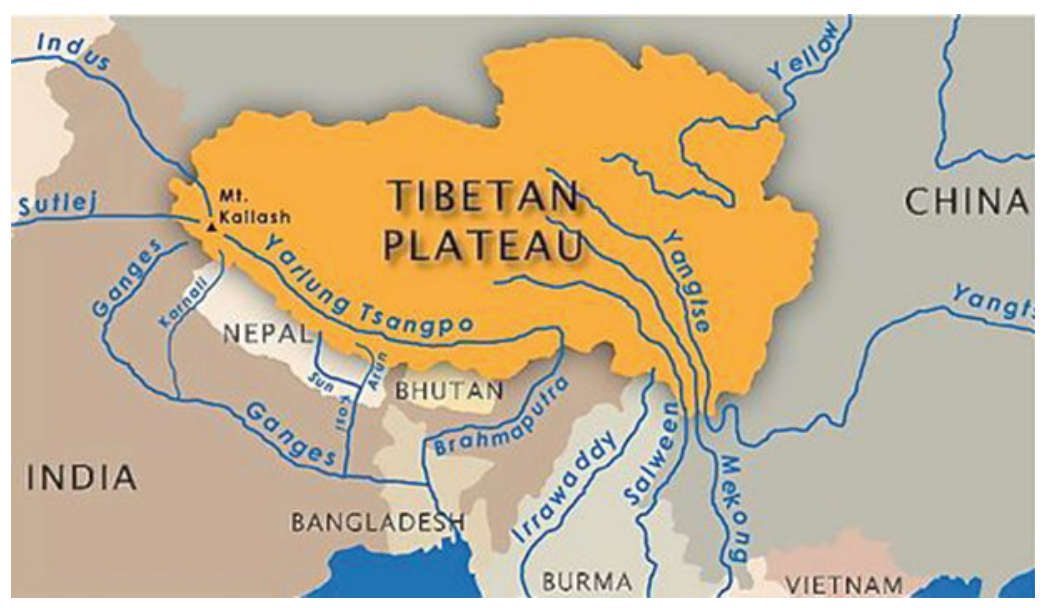


Chinese authorities have long had their eyes on Tibet's water resources. They have proposed building dams for hydropower and spending billions of dollars to build a system of canals to tap water from the Himalayan snowmelt and glaciers and transport it hundreds of miles north and east to the country's farm and industrial regions.

But how long that frozen reservoir will last is in doubt. In attempting to solve its own water crisis, China could potentially create widespread water shortages among its neighbors.

While the political issues involving Tibet are complex, there is no denying that water plays a role in China's interest in the region. The water of Tibet may prove to be one of its most important resources in the long run-for China, and for much of southern Asia. Figuring out how to sustainably manage that water will be a key to reducing political conflicts and tensions in the region.

\subsubsection{Managing Sediment in China's Yellow River}

The scarcity of water is not the only issue China has to address. So is sediment, especially in the Yellow River (Fig. 1.18). The Yellow River basin is the cradle of Chinese civilization, with agricultural societies appearing on the banks of the river more than 7000 years ago. The Yellow River originates in the Qinghai-Tibetan plateau and discharges into the Bohai Gulf in the Yellow sea. The basin is traditionally divided into the upper, middle, and lower reaches, which can be described as three down-sloping steps: the Tibetan Plateau, the Loess Plateau, and the alluvial plain. Key management issues are many, but the most visible one is sediment (Figs. 1.19 and 1.20).

The high sediment load of the Yellow River is a curse if the sediment deposits on the bed of the channel and reduces its capacity, thereby increasing the risk of flooding. Also, rapid deposition of sediment in reservoirs situated along the river is a problem as it reduces their effectiveness for flood control and water storage.
Another major management issue is the ecosystem health of the river. The relative scarcity of water creates a tension between allocating water for the benefit of river health, and for direct social and economic benefit. Irrigation uses $80 \%$ of the water consumed from the river, with the rest supplying industry, and drinking water for cities along the river and outside of the basin (Tianjin, Cangzhou and Qingdao). During the 1980s and 1990s the lower river dried up nearly every year, resulting in lost cereal production, suspension of some industries, and insufficient water supplies for more than 100,000 residents, who had to queue daily for drinking water. As well as costing around $\mathrm{RmB} 40$ billion in lost production, there was a serious decline in the ecological health of the river.

The diversity of habitat types and extensive areas of wetlands within the Ramsar-listed Yellow River Delta support at least 265 bird species. The birds, fish, and macroinvertebrates in the delta rely on healthy and diverse vegetation communities, which in turn depend upon on annual freshwater flooding and the associated high sediment loads. Degradation of the ecosystem of the Delta has been documented, especially from the late-1990s, due to increased human activities and a significant decrease in the flow of freshwater to the Delta wetlands. This has led to saltwater intrusion and increased soil salinity. Restoration activities involving the artificial delivery of freshwater to the wetlands began in 2002 .

\subsubsection{Damming the Mekong (S.E. Asia), the Amazon, and the Congo}

The world's most biodiverse river basins - the Amazon, Congo, and Mekong - are attracting hydropower developers. While hydropower projects address energy needs and offer the potential of a higher standard of living, they also can impact the river's biodiversity, especially fisheries. The Amazon, Congo, and Mekong basins hold roughly one-third of the world's freshwater 


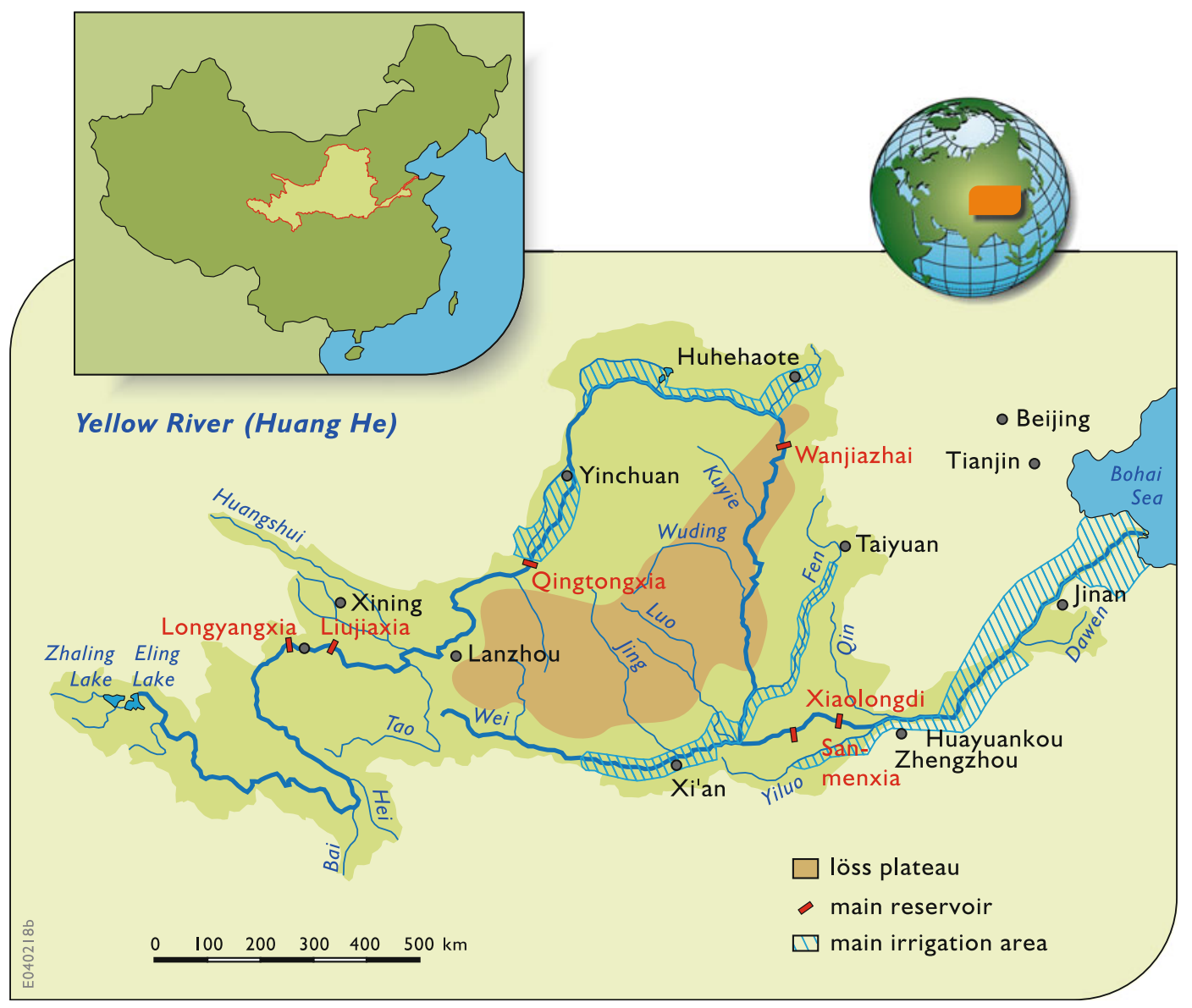

Fig. 1.18 The Yellow River Basin in China

fish species, most of which are not found elsewhere. Currently more than 450 additional dams are planned for these three rivers (see Figs. 1.22 and 1.23) (Winemiller et al. 2016). Many of the sites most appropriate for hydropower production also are the habitats of many fish species. Given recent escalation of hydropower development in these basins, planning is needed to reduce biodiversity loss, as well as other adverse environmental, social, and economic impacts while meeting the energy needs of the basins.

The Mekong River (Fig. 1.21) flows some $4200 \mathrm{~km}$ through Southeast Asia to the South China Sea through Tibet, Myanmar (Burma), Vietnam, Laos, Thailand, and Cambodia. Its "development" has been restricted over the past several decades due to regional conflicts, indeed conflicts that have altered the history of the world. Now that these conflicts are not resulting in military battles (at this writing), investment capital is becoming available to develop the Mekong's resources for improved fishing, irrigation, flood control, hydroelectric power, tourism, recreation, and navigation. The potential benefits are substantial, but so are the environmental, ecological, and social risks (Orr et al. 2012).

The economic value of hydroelectric power currently generated from the Mekong brings in welcome income however the environmental impacts are harder to quantify. Today some 60 million people (12 million households) live in the Lower Mekong Basin, and 80\% rely directly 


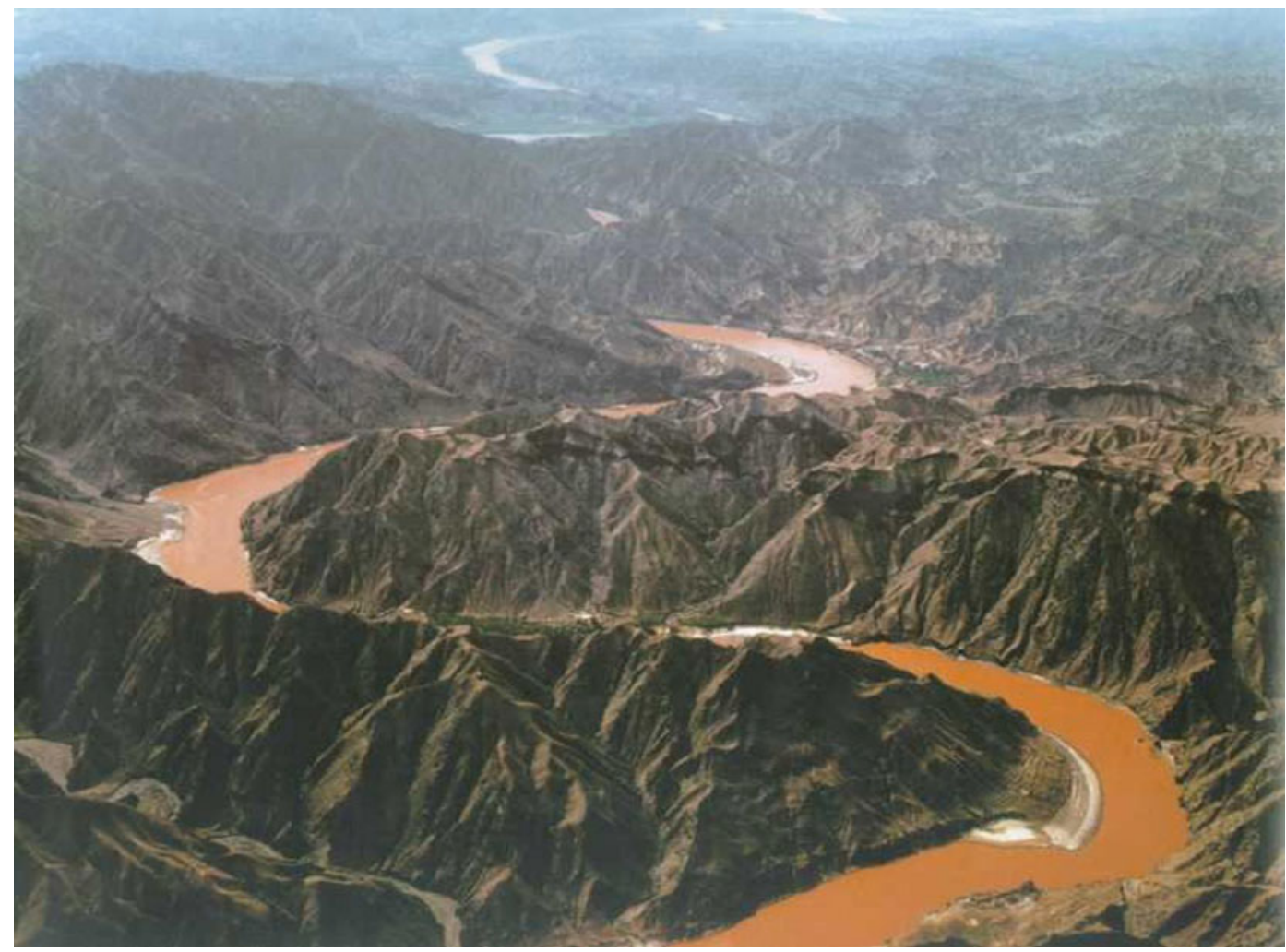

Fig. 1.19 Sediment flows in China's Yellow River. http://yellowriver-china.blogspot.com/2011/09/book-review-onflood-discharge-and.html

on the river system for their food and livelihoods. Most of these households would be affected by alterations to fish availability since fish is their main source of dietary protein. The food security impacts on these people due to the existing and proposed dam building and operation in Cambodia, Laos, Thailand, and Vietnam remain relatively unexplored. Dam builders have often failed to recognize, or wish to ignore, the crucial role of inland fisheries in meeting food security needs.

During some months of the year the lack of rainfall causes the Mekong to fall dramatically. Salt water may penetrate as much as $500 \mathrm{~km}$ inland. In other months the flow can be up to 30 times the low flows, causing the water in the river to back up into wetlands and flood some $12,000 \mathrm{~km}^{2}$ of forests and paddy fields in the
Vietnamese delta region alone. The ecology of a major lake, Tonle Sap, in Cambodia depends on these backed up waters.

While flooding imposes risks on the inhabitants of the Mekong flood plain, there are also distinct advantages. High waters deposit nutrient-rich silts on the low-lying farmlands, thus sparing the farmers from having to transport and spread fertilizers on their fields. Also, shallow lakes and submerged lands provide spawning habitats for about $90 \%$ of the fish in the Mekong basin. Fish yield totals over half a million tons annually.

What will happen to the social fabric and to the natural environment if the schemes to build big dams (see Fig. 1.22a) across the mainstream of the Mekong are implemented? Depending on their design, location, and operation, they could 
Fig. 1.20 Dams can be designed and operated to remove some of the sediment that is trapped in the upstream reservoir

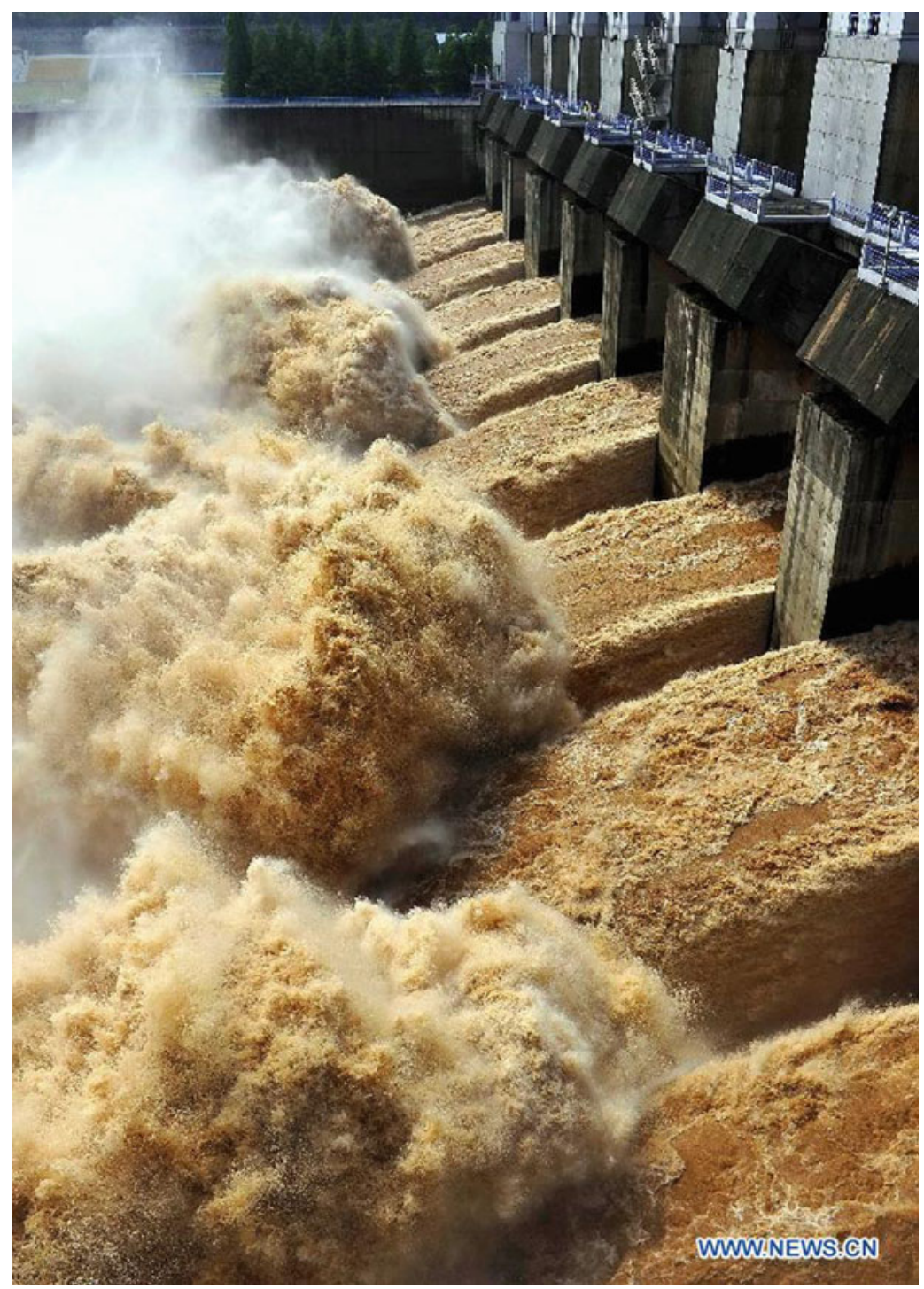

disrupt the current fertility cycles and the habitats and habits of the fish in the river resulting from the natural flow and sediment regimes. Increased erosion downstream from major reservoirs is also a threat. Add to these possible adverse impacts the need to evacuate and resettle thousands of people displaced by the lake behind the dams. How will they be resettled? And how long will it take them to adjust to new farming conditions? And will there even be a Delta? Together with sea level rise and a blockage of Mekong's sediment to the Delta, its survival as a geologic feature, and as a major source of food, is in doubt.

There have been suggestions that a proposed dam in Laos could cause deforestation in a wilderness area of some $3000 \mathrm{~km}^{2}$. Much of the wildlife, including elephants, big cats, and other rare animals, would have to be protected if they are not to become endangered. Malaria-carrying mosquitoes, liver fluke, and other disease bearers might find ideal breeding grounds in the mud flats of the shallow reservoir. These are among 




Fig. 1.21 The Lower Mekong River Basin including Tonle Sap Lake in Cambodia and the Mekong Delta in Vietnam 
(a)

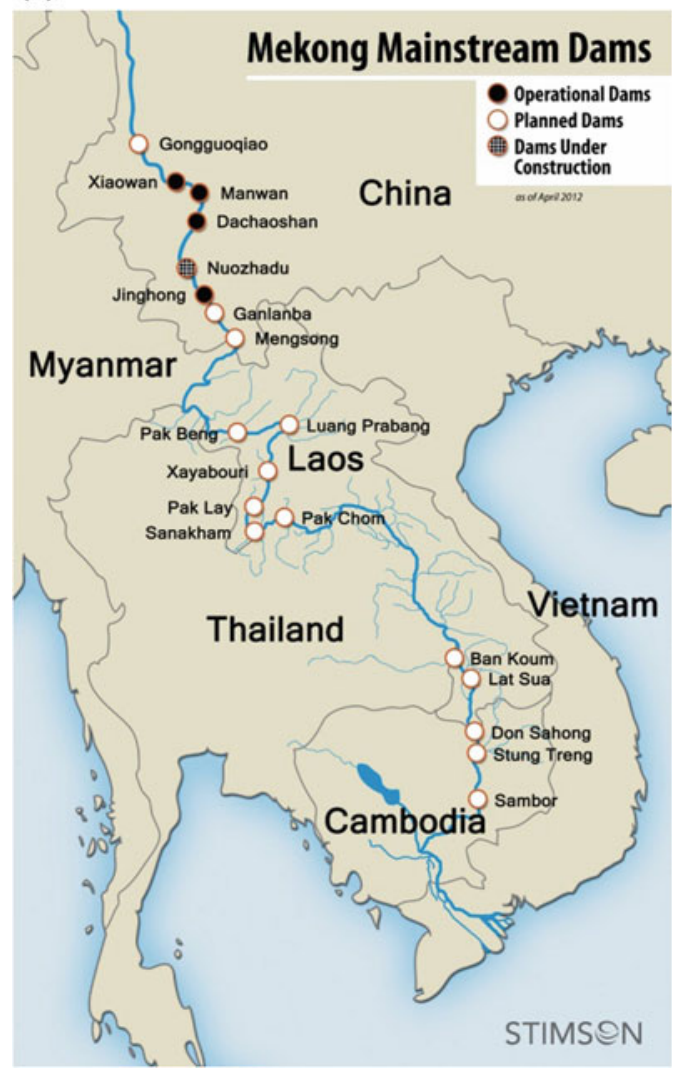

Fig. 1.22 Lancang/Mekong River where reservoirs are being planned on the river itself (a) and on many of its tributaries (b). a http://khmerization.blogspot.com/2013/ 10/wwf-expresses-alarm-over-laos-decision.html, 6/10/ 13, and b reprinted from Wild and Loucks 2014, with permission. (C) 2014. American Geophysical Union

the types of issues that need to be considered now that increased development seems likely.

Similar issues face those who are planning similar hydropower dam developments in the other two most biodiverse river basins in the world - the Amazon and the Congo (Fig. 1.23). Clarifying the trade-offs between energy (economic), environmental, and social goals can inform governments and funding institutions as they make their dam siting, design, and operating decisions.

Hydropower accounts for more than two-thirds of Brazil's energy supply, and over 300 new Amazon dams have been proposed. Impacts of these dams would extend beyond direct effects on rivers to include relocation of human populations and expanding deforestation associated with new roads. Scheduled for completion in 2016, Brazil's Belo Monte hydropower complex was designed with installed capacity of 11,233 MW, ranking it the world's third largest. But it could also set a record for biodiversity loss owing to selection of a site that is the sole habitat for many species. The Congo has far fewer dams than the Amazon or Mekong, yet most power generated within the basin is from hydropower. Inga Falls, a 14.5-km stretch of the lower Congo that drops $96 \mathrm{~m}$ to near sea level, has greater hydropower potential than anywhere else. The Inga I and II dams, constructed in the 1970s and 1980 s, currently yield $40 \%$ of the 2132-MW installed capacity. Planned additional dams (Inga III and Grand Inga) would harness as much as $83 \%$ of the Congo's annual discharge, with most of the energy to be exported. Grand Inga would divert water and substantially reduce flow for at least $20 \mathrm{~km}$ downstream from the falls. Again, many trade-offs involved with dam building, and all calling for comprehensive systems planning and analyses to identify them.

\subsection{So, Why Plan, Why Manage?}

Water resources planning and management activities are usually motivated, as they were in each of the previous section's case examples, by the realization that there are problems to solve and/or opportunities to obtain increased benefits by changing the management and use of water and related land resources. These benefits can be measured in many different ways. The best way to do it is often not obvious. Whatever way is proposed may provoke conflict. Hence there is the need for careful study and research, as well as full stakeholder involvement, in the search for the best compromise plan or management policy.

Reducing the frequency and/or severity of the adverse consequences of droughts, floods, and excessive pollution are common goals of many planning and management exercises. Other reasons include the identification and evaluation of alternative measures that may increase the available water supplies, hydropower, improve 
(b)

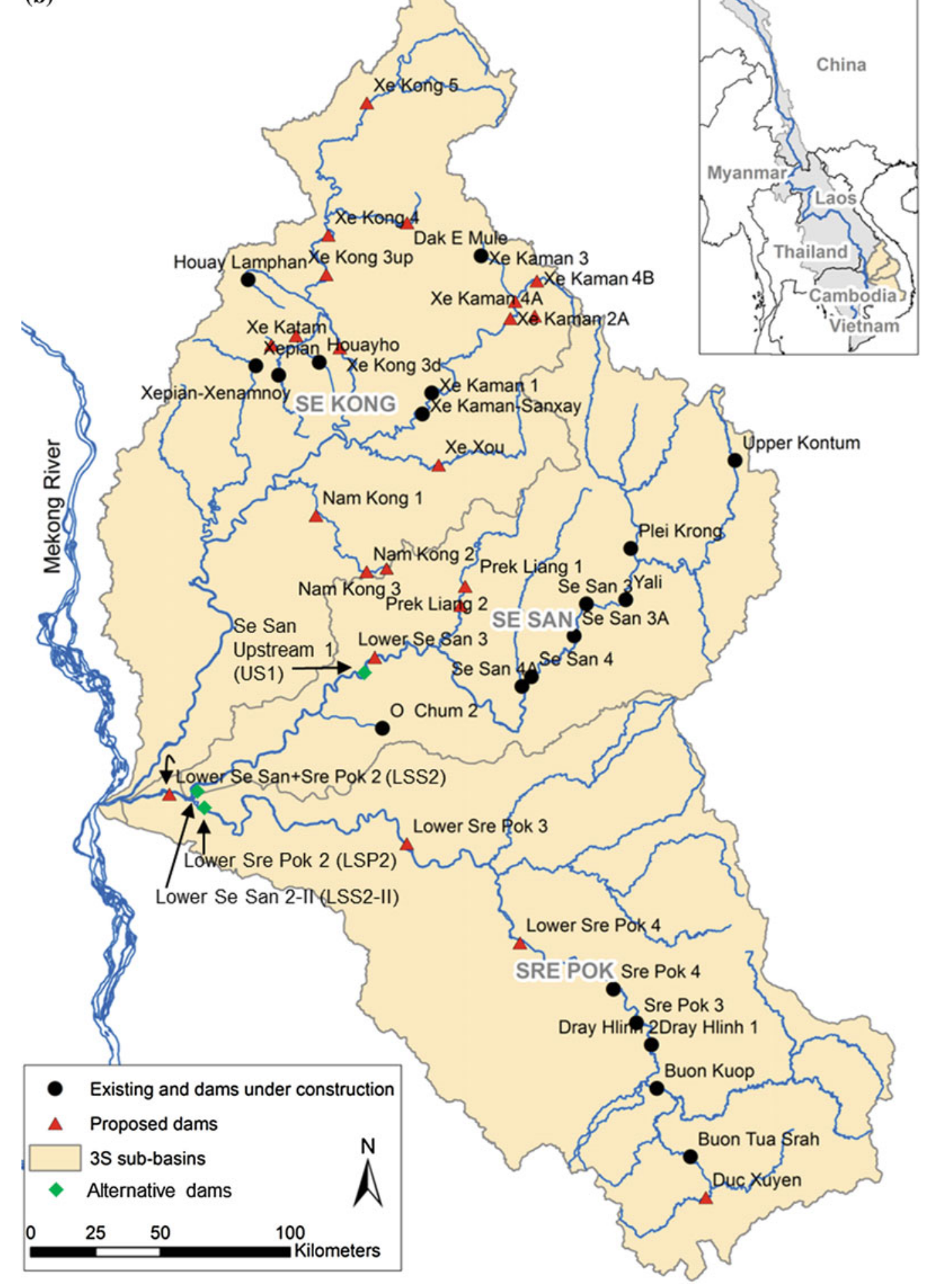

Fig. 1.22 (continued) 

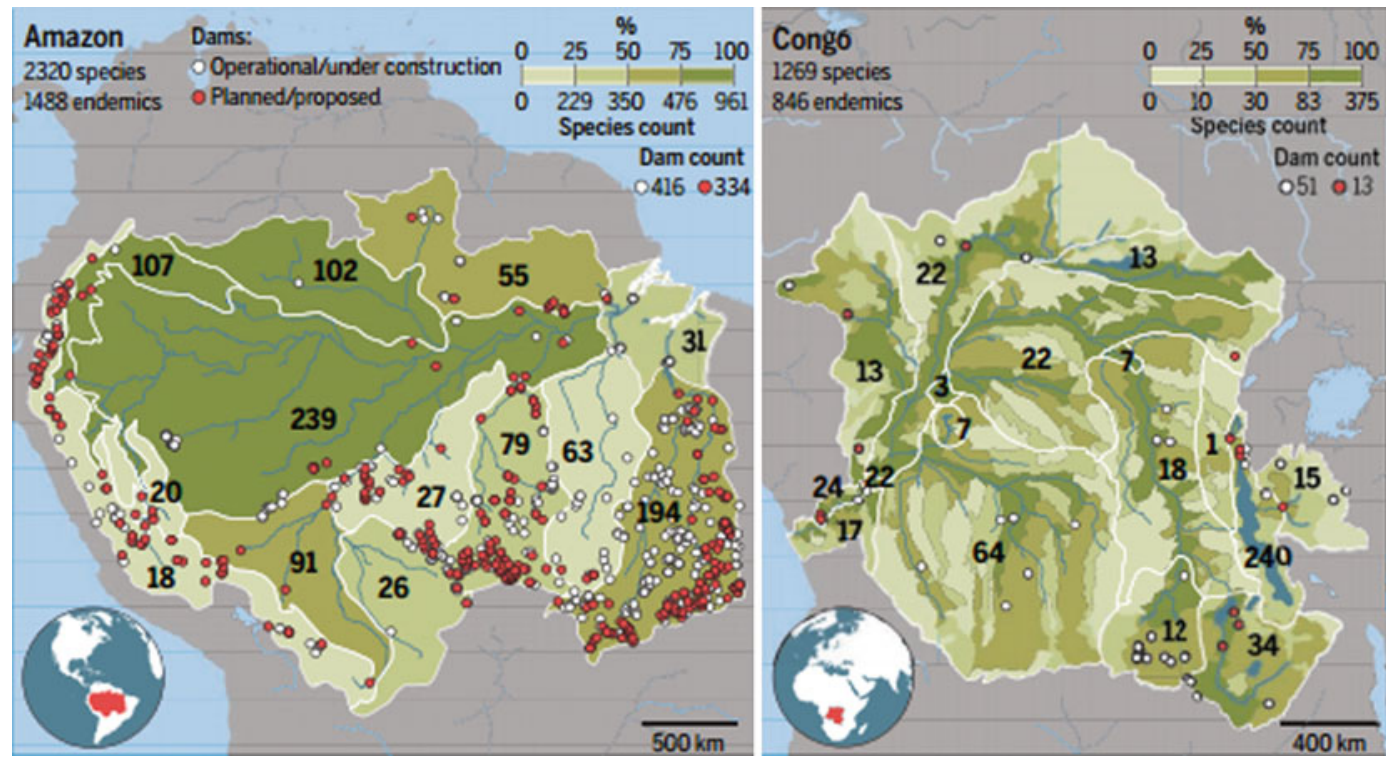
Amazon and Congo basins. In addition to basin-wide biodiversity summaries (upper left), each basin can be divided into ecoregions (white boundaries). Approximate
Fig. 1.23 Fish diversity and dam locations in the

number of species (black numbers) and the total species richness (shades of green) found in ecoregions differ widely (Winemiller et al. 2016)

demands exceed the available supplies, conflicts will exist over water allocations. Finding the best way to manage, if not resolve, these conflicts are reasons for planning.

\subsubsection{Too Little Water}

evolved over time. They have ranged from being primarily focused on safe drinking water just a century ago to multipurpose economic development a half-century ago to goals that now include environmental and ecosystem restoration and protection, aesthetic and recreational experiences, and more recently, sustainability (ASCE 1998; GTT 2014).

Some of the multiple purposes served by a river can be conflicting. A reservoir used solely for hydropower, or water supply, is better able to meet its objectives when it is full of water. On the other hand, a reservoir used solely for downstream flood control is best left empty so it can store more of the flood flows when they occur. A single reservoir serving all three purposes introduces conflicts over how much water to store in it and discharge from it, i.e., how it should be operated. In basins where diversion
Issues involving inadequate supplies to meet demands can result from too little rain or snow. They can also result from patterns of land and water use. They can result from growing urbanization, the growing needs to meet instream flow requirements, and conflicts over private property and public rights regarding water allocations. Other issues can involve transbasin water transfers and markets, objectives of economic efficiency versus the desire to keep nonefficient activities viable, and demand management measures, including incentives for water reuse and water reuse financing.

Measures to reduce the demand for water in times of supply scarcity should be identified and agreed upon before everyone must cope with an actual water scarcity. The institutional authority 
to implement drought measures when their designated "triggers"- such as storage volumes in reservoirs - have been met should be established before they are needed. Such management measures may include increased groundwater abstractions to supplement low-surface water flows and storage volumes. Conjunctive use of ground and surface waters can be sustainable as long as the groundwater aquifers are recharged during conditions of high flow and surface storage volumes. Many aquifers are subject to withdrawals exceeding recharge, and hence continued withdrawals from them cannot be sustained.

\subsubsection{Too Much Water}

Damage due to flooding is a direct result of floodplain development that is incompatible with floods. This is a risk many take, and indeed on average it may result in positive private net benefits, especially when public agencies subsidize these private risk takers who incur losses in times of flooding. In many river basins of developed regions, annual expected flood damages are increasing over time, in spite of increased expenditures in flood damage reduction measures. This is in part due to increased economic development taking place on river flood plains, not only of increased frequencies and magnitudes of floods.

The increased economic value of developments on floodplains often justifies increased development and increased expenditures on flood damage reduction measures. Flood protection works decrease the risks of flood damage, creating an even larger incentive for increased economic development. Then when a flood exceeding the capacity of existing flood protection works occurs, and it will, even more damage results. This cycle of increasing flood damages and costs of protection is a natural result of increasing values of flood plain development. Just what is the appropriate level of risk? It may depend, as Fig. 1.24 illustrates, on the level of flood insurance or subsidy provided when flooding occurs.

Flood damages will decrease only if there are restrictions placed on floodplain development.

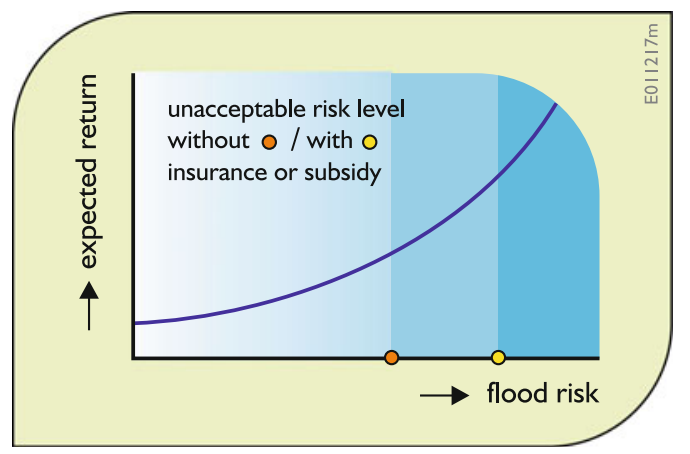

Fig. 1.24 The lowest risk of flooding on a floodplain does not always mean the best risk, and what risk is acceptable may depend on the amount of insurance or subsidy provided when flood damage occurs

Analyses carried out during planning can help identify the appropriate level of development and flood damage protection works based on the beneficial as well as adverse economic, environmental, and ecological consequences of flood plain development. People are increasingly recognizing the economic as well as environmental and ecological benefits of allowing floodplains to do what they were formed to do-store flood waters when floods occur.

Industrial development and related port development may result in the demand for deeper and wider rivers to allow the operation of larger draft cargo vessels in the river. River channel improvement cannot be detached from functions such as water supply and flood control. Widening and deepening a river channel for shipping purposes may also decrease flood water levels.

\subsubsection{Too Polluted}

Wastewater discharges by industry and households can have considerable detrimental effects on water quality and hence on public and ecosystem health. Planning and management activities should pay attention to these possible negative consequences of industrial development and the intensive use and subsequent runoff of pesticides and fertilizers in urban as well as in agricultural areas.

Issues regarding the environment and water quality include: 
- Upstream versus downstream conflicts on meeting water quality standards,

- Threats from aquatic nuisance species,

- Threats from the chemical, physical, and biological water quality of the watershed's aquatic resources,

- Quality standards for recycled water,

- Nonpoint source pollution discharges including sediment from erosion, and

- Inadequate groundwater protection, compacts, and concerned institutions.

We still know too little about the environmental and health impacts of many of the wastewater constituents found in river waters. As more is learned about, for example, the harmful effects of heavy metals and dioxins, pharmaceutical products, and micropollutants and nanoparticles in our water supplies, water quality standards, plans and management policies should be adjusted accordingly. The occurrence of major fish kills and algae blooms also point to the need to manage water quality as well as quantity.

\subsubsection{Too Expensive}

Too many of the world's population do not have adequate water to meet all of their drinking and sanitation needs. Much of this is not due to the lack of technical options available to provide water to meet those needs. Rather those options are deemed to be too expensive. Doing so is judged to be beyond the ability of those living in poverty to pay and recover the costs of implementing, maintaining, and operating the needed infrastructure. Large national and international aid grants devoted to reducing water stressdemands for clean water exceeding usable supplies - in stressed communities have not been sustainable in the long run where recipients have been unable to pay for the upkeep of whatever water resource systems are developed and provided. If financial aid is to be provided, to be effective it has to address all the root causes of such poverty, not only the need for clean water.

\subsubsection{Ecosystem Too Degraded}

Aquatic and riparian ecosystems may be subject to a number of threats. The most important ones include habitat loss due to river training and reclamation of floodplains and wetlands for urban and industrial development, poor water quality due to discharges of pesticides, fertilizers and wastewater effluents, and the infestation of aquatic nuisance species.

Exotic aquatic nuisance species can be major threats to the chemical, physical, and biological water quality of a river's aquatic resources and a major interference with other uses. The destruction and/or loss of the biological integrity of aquatic habitats caused by introduced exotic species is considered by many ecologists to be among the most important problems facing natural aquatic and terrestrial ecosystems. Biological integrity of natural ecosystems is controlled by habitat quality, water flows or discharges, water quality, and biological interactions including those involving exotic species.

Once exotic species are established, they are usually difficult to manage and nearly impossible to eliminate. This creates a costly burden for current and future generations. The invasion in North America of nonindigenous aquatic nuisance species such as the sea lamprey, zebra mussel, purple loosestrife, European green crab, and various aquatic plant species, for example, has had pronounced economic and ecological consequences for all who use or otherwise benefit from aquatic ecosystems.

Environmental and ecological effectiveness as well as economic efficiency should be a guiding principle in evaluating alternative solutions to problems caused by aquatic nuisance organisms. Funds spent in prevention and early detection and eradication of aquatic nuisance species may 
reduce the need to spend considerably more funds on management and control once such aquatic nuisance species are well established.

\subsubsection{Other Planning and Management Issues}

\subsubsection{Navigation}

Dredging river beds is a common practice to keep river channels open for larger draft cargo ships. The use of jetties as a way to increase the flow in the main channel and hence increase bottom scour is a way to reduce the amount of dredging that may be needed, but any modification of the width and depth of a river channel can impact its flood carrying capacity. It can also alter the periodic flooding of the floodplain that in turn can have ecological impacts.

\subsubsection{River Bank Erosion}

Bank erosion can be a serious problem where towns are located close to morphologically active (eroding) rivers. Predictions of changes in river courses due to bank erosion and bank accretion are important inputs to land use planning in river valleys and the choice of locations for bridges, buildings, and hydraulic structures.

\subsubsection{Reservoir Related Issues}

Degradation of the riverbeds upstream of reservoirs may increase the risks of flooding in those areas. Reservoir construction inevitably results in loss of land and forces the evacuation of residents due to impoundment. Reservoirs can be ecological barriers for migrating fish species such as salmon. The water quality in the reservoir may deteriorate and the inflowing sediment may settle and accumulate, reducing the active (useful) water storage capacity of the reservoir and causing more erosion downstream. Other potential problems may include those stemming from stratification, water-related diseases, algae growth, and abrasion of hydropower turbines.

Environmental and morphological impacts downstream of the dam are often due to a changed river hydrograph and decreased sediment load in the water released from the reservoir. Lower sediment concentrations result in higher risks of scouring of downstream riverbeds and consequently a lowering of their elevations. Economic as well as social impacts include the risk of a dam break. Environmental impacts may result from sedimentation control measures (e.g., sediment flushing as shown in Fig. 1.19) and reduced oxygen content of the outflowing water.

\subsection{System Planning Scales}

\subsubsection{Spatial Scales for Planning and Management}

Watersheds or river basins are usually considered logical regions for water resources planning and management. This makes sense if the impacts of decisions regarding water resources management are contained within the watershed or basin. How land and water are managed in one part of a river basin can impact the land and water in other parts of the basin. For example, the discharge of pollutants or the clearing of forests in the upstream portion of the basin may degrade the quality and increase the variability of the flows and sedimentation downstream. The construction of a dam or weir in the downstream part of a river may block vessels and fish from traveling up- or downstream through the dam site. To maximize the economic and social benefits obtained from the entire basin, and to insure that these benefits and accompanying costs are equitably distributed, planning and management on a basin scale is often undertaken.

While basin boundaries make sense from a hydrologic point of view, they may be inadequate for addressing particular water resources problems that are caused by events taking place outside the basin. What is desired is the highest level of performance, however defined, of the entire physical, social-economic, and administrative water resource system. To the extent that the applicable problems, stakeholders, and administrative boundaries extend outside the 
river basin, then the physically based "river basin" focus of planning and management should be expanded to include the entire applicable "problem-shed." Hence consider the term "river basin" used in this book to mean problem-shed when appropriate.

\subsubsection{Temporal Scales for Planning and Management}

Planning is a continuing iterative process. Water resources plans need to be periodically updated and adapt to new information, new objectives, and updated forecasts of future demands, costs, and benefits. Current decisions should not preclude future generations from options they may want to consider, but otherwise current decisions should be responsive to current needs and opportunities, and have the ability to be adaptable in the future to possible changes in those needs and opportunities.

The number and duration of within-year time periods explicitly considered in the planning process will depend in part on the need to consider the variability of the supplies of and demands for water resources and on the purposes to be served by the water resources. Irrigation planning and summer season water recreation planning may require a greater number of within-year periods during the summer growing and recreation season than might be the case if one were considering only municipal water supply planning, for example. Assessing the impacts of alternatives for conjunctive surface and groundwater management, or for water quantity and quality management, require attention to processes that typically take place on different spatial and temporal scales.

\subsection{Planning and Management Approaches}

There are two general approaches to planning and management. One is from the top-down, often called command and control. The other is from the bottom-up, often called the grassroots approach.
Both approaches, working together, can lead to an integrated plan and management policy.

\subsubsection{Top-Down Planning and Management}

Over much of the past half-century water resources professionals have been engaged in preparing integrated, multipurpose "master" development plans for many of the world's river basins. These plans typically consist of a series of reports, complete with numerous appendices, describing all aspects of water resources management and use. In these documents alternative structural and nonstructural management options are identified and evaluated. Based on these evaluations, the preferred plan is recommended.

This master planning exercise has typically been a top-down approach. Professionals have dominated the top-down approach. Using this approach there is typically little if any active participation of interested stakeholders. The approach assumes that one or more institutions have the ability and authority to develop and implement the plan, i.e., to oversee and manage the coordinated development and operation of the basin's activities impacting the surface and ground waters of the basin. In today's environment where publics are calling for less government oversight, regulation and control, and increasing participation in planning and management activities, strictly top-down approaches are becoming less desirable or acceptable.

\subsubsection{Bottom-Up Planning and Management}

Within the past several decades water resources planning and management processes have increasingly involved the active participation of interested stakeholders - those potentially affected by the decision being considered. Plans are being created from the bottom-up rather than top-down through a process of consensus building. Concerned citizens, nongovernmental organizations, as well as professionals in 
governmental agencies are increasingly working together toward the creation of adaptive comprehensive water management programs, policies, and plans.

Experiences trying to implement plans developed primarily by professionals without significant citizen involvement have shown that even if such plans are technically sound they have little chance of success if they do not take into consideration the concerns and objectives of affected stakeholders. To gain their support, concerned stakeholders must be included in the decision-making process as early as possible. They must become part of the decision-making process, not merely spectators, or even advisors, to it. This will help gain their cooperation and commitment to the plans eventually adopted. Participating stakeholders will consider the resulting plans as their plans as much as someone else's. They will have a sense of ownership, and as such will strive to make them work. Such adopted plans, if they are to be successfully implemented, must fit within existing legislative, permitting, enforcement, and monitoring programs. Stakeholder participation improves the chance that the system being managed will be sustainable.

Successful planning and management involves motivating all potential stakeholders and sponsors to join and participate in the water resources planning and management process. It will involve building a consensus on goals and objectives and on how to achieve them. Ideally this should occur before addressing conflicting issues so that all involved know each other and are able to work together more effectively. Agreements on goals and objectives and on the organization (or group formed from multiple organizations) that will lead and coordinate the water resources planning and management process should be reached before stakeholders bring their individual priorities or problems to the table. Once the inevitable conflicts become identified, the settling of administrative matters does not get any easier.

Bottom-up planning must strive to achieve a common or "shared" vision among all stakeholders. It must either comply with all applicable laws and regulations, or propose changes to them. It should strive to identify and evaluate multiple alternatives and performance criteriaincluding sustainability criteria, and yet keep the process from producing a wish list of everything each stakeholder wants. In other words, it must identify trade-offs among conflicting goals or measures of performance, and prioritizing appropriate strategies. It must value and compare, somehow, the intangible and nonmonetary impacts of environmental and ecosystem protection and restoration with other activities whose benefits and costs can be expressed in monetary units. In doing all this, planners should use modern information technology, as available, to improve both the process and product. This technology, however, will not eliminate the need to reach conclusions and make decisions on the basis of incomplete and uncertain data and scientific knowledge.

These process issues emphasize the need to make water resources planning and management as efficient and effective as possible and remain participatory. Many issues will arise in terms of evaluating alternatives and establishing performance criteria (prioritizing issues and possible actions), performing incremental cost analysis, and valuing monetary and nonmonetary benefits. Questions must be answered as to how much data must be collected and with what precision, and what types of modern information technology (e.g., geographic information systems (GIS), remote sensing, Internet and mobile Internet networks, decision support systems, etc.) can be beneficially used both for analyses as well as communication. 


\subsubsection{Integrated Water Resources Management}

The concept of integrated water resources management (IWRM) has been developing over the past several decades. IWRM is the response to the growing pressure on our water resources systems caused by growing populations and socioeconomic developments. Water shortages and deteriorating water quality have forced many countries in the world to reconsider their development policies with respect to the management of their water resources. As a result water resources management (WRM) has been undergoing a change worldwide, moving from a mainly supply-oriented, engineering-biased approach toward a demand-oriented, multisectoral approach, often labeled integrated water resources management.

The concept of IWRM moves away from top-down "water master planning" that usually focuses on water availability and development, and toward "comprehensive water policy planning" that addresses the interaction between different subsectors (Fig. 1.25), seeks to establish priorities, considers institutional requirements, and deals with the building of management capacity.

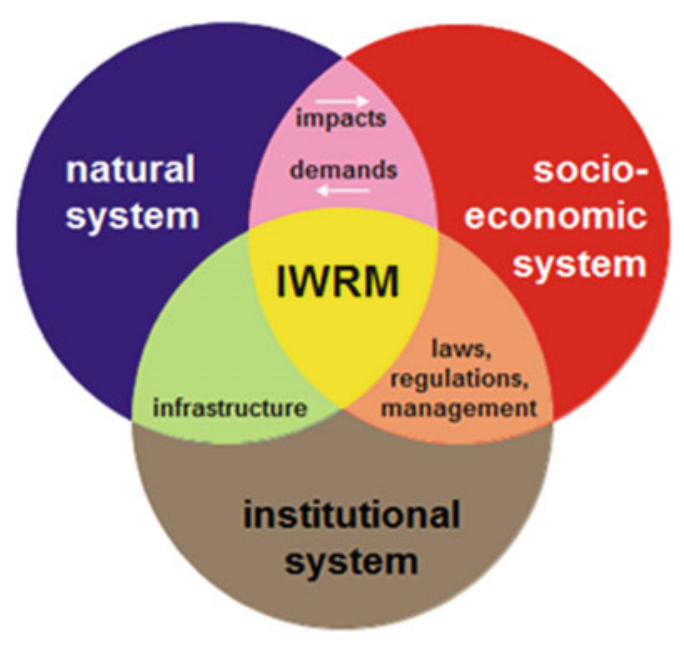

Fig. 1.25 Interactions among the natural, administrative, and socioeconomic water resource subsectors and between them and their environment

\section{Box 1.1 Definition of IWRM}

IWRM is a process which promotes the coordinated development and management of water, land, and related resources, in order to maximize the resultant economic and social welfare in an equitable manner without compromising the sustainability of vital ecosystems.

(GWP 2000)

IWRM (Box 1.1) considers the use of the resources in relation to social and economic activities and functions. These determine the need for laws and regulations pertaining to the sustainable and beneficial use of the water resources. Infrastructure together with regulatory measures allows more effective use of the resource including meeting ecosystem needs.

\subsubsection{Water Security and the Sustainable Development Goals (SDGs)}

While IWRM focuses on the process to improve water management (the how), the term "water security" focuses on the output (the what). The World Economic Forum has identified Water Security as one of the biggest global economic development issues. Water Security is defined by UN-Water (2013) as

\footnotetext{
the capacity of a population to safeguard sustainable access to adequate quantities of acceptable quality water for sustaining livelihoods, human well-being, and socio-economic development, for ensuring protection against water-borne pollution and water-related disasters, and for preserving ecosystems in a climate of peace and political stability.
}

Attempts are being made to identify the many dimensions of water security and to quantify them (van Beek and Arriens 2014; ADB 2016). In 2015 the UN adopted the Sustainable Development Goals 2015-2030 that specify specific 
targets for various goals such as the provision of water for drinking and sanitation, water productivity in agriculture, industry and energy, environment, and reduction of floods and droughts. It is expected that many countries will expect their water managers to use the SDGs as objectives in water resources planning. This means that our planning and management proposals need to be able to quantify the impacts of possible plans and policies in terms of the SDG targets.

\subsubsection{Planning and Management Aspects}

\subsubsection{Technical}

Technical aspects of planning include hydrologic assessments. Hydrologic assessments identify and characterize the properties of, and interactions among, the resources in the basin or region. This includes the land, the rainfall, the runoff, the stream and river flows, and the groundwater.

Existing watershed land use and land cover, and future changes in this use and cover, result in part from existing and future changes in regional population and economy. Planning involves predicting changes in land use/covers and economic activities at watershed and river basin levels. These will influence the amount of runoff, and the concentrations of sediment and other quality constituents (organic wastes, nutrients, pesticides, etc.) in the runoff resulting from any given pattern of rainfall over the land area. These predictions will help planners estimate the quantities and qualities of flows throughout a watershed or basin, associated with any land use and water management policy. This in turn provides the basis for predicting the type and health of terrestrial and aquatic ecosystems in the basin. All of this may impact the economic development of the region, which is what, in part, determines the future demands for changes in land use and land cover.

Technical aspects also include the estimation of the costs and benefits of any measures taken to manage the basin's water resources. These measures might include:
- Engineering structures for making better use of scarce water.

- Canals and water-lifting devices.

- Dams and storage reservoirs that can retain excess water from periods of high flow for use during the periods of low flow. By storage of floodwater they may also reduce flood damage below the reservoir.

- Open channels that may take the form of a canal, flume, tunnel, or partly filled pipe.

- Pressure conduits.

- Diversion structures, ditches, pipes, checks, flow dividers, and other engineering facilities necessary for the effective operation of irrigation and drainage systems.

- Municipal and industrial water intakes, including water purification plants and transmission facilities.

- Sewerage and industrial wastewater treatment plants, including waste collection and ultimate disposal facilities.

- Hydroelectric power storage, run-of-river, or pumped storage plants.

- River channel regulation works, bank stabilization, navigation dams and barrages, navigation locks, and other engineering facilities for improving a river for navigation.

- Levees and floodwalls for confining flows within predetermined channels.

Not only must the planning process identify and evaluate alternative management strategies involving structural and nonstructural measures that will incur costs and bring benefits, but it must also identify and evaluate alternative time schedules for implementing those measures. The planning of development over time involving interdependent projects, uncertain future supplies and demands as well as costs, benefits, and interest (discount) rates is part of all water resources planning and management processes.

With increasing emphasis placed on ecosystem preservation and enhancement, planning must include ecologic impact assessments. The mix of soil types and depths and land covers together with the hydrological quantity and quality flow and storage regimes in rivers, lakes, wetlands, and 
aquifers all impact the riparian and aquatic ecology of the basin. Water managers are being asked to consider ways of improving or restoring ecosystems by, for example, reducing the

- destruction and/or loss of the biological integrity of aquatic habitats caused by introduced exotic species or changes in flow and sediment patterns due to upstream reservoir operation.

- decline in number and extent of wetlands and the adverse impacts to wetlands of proposed land and water development projects.

- conflicts between the needs of people for water supply, recreational, energy, flood control, and navigation infrastructure and the needs of ecological communities, including endangered species.

And indeed there are and will continue to be conflicts among alternative objectives and purposes of water management. Planners and managers must identify the trade-offs among environmental, ecologic, economic, and social impacts, however measured, and the management alternatives that balance these often-conflicting interests.

\subsubsection{Financial and Economic}

The overriding financial component of any planning process is to make sure that the recommended plans and projects will be able to pay for themselves. Revenues are needed to recover construction costs, if any, and to maintain, repair, and operate any infrastructure designed to manage the basin's water resources. This may require cost-recovery policies that involve pricing the outputs of projects. Recognizing water as an economic good does not always mean that full costs should be charged. Poor people have the right to safe water and how this is to be achieved should be taken into account. Yet beneficiaries should be expected to pay at least something for the added benefits they get. Planning must identify equitable cost and risk-sharing policies and improved approaches to risk/cost management.
Financial viability is often viewed as a constraint that must be satisfied. It is not viewed as an objective whose maximization could result in a reduction in economic efficiency, equity, or other nonmonetary objectives. In many developing countries a distinction is made between the recovery of investment costs and the recovery of O\&M costs. Recovery of O\&M costs is a minimum condition for a sustainable project. Without that, it is likely that the performance of the project will deteriorate over time.

Many past failures in water resources management are attributable to the fact that water-its quantity, reliability, quality, pressure, locationhas been and still is viewed as a free good. Prices paid for irrigation and drinking water are in many countries well below the full cost of the infrastructure and personnel needed to provide that water, which comprises the capital charges involved, the operation and maintenance (O\&M) costs, the opportunity cost, economic and environmental externalities (see GWP 2000). Charging for water at less than full cost means that the government, society, and/or environment "subsidizes" water use and leads to an inefficient use of the resource.

\subsubsection{Institutional and Governance}

The first condition for the successful implementation of plans and policies is to have an enabling environment. There must exist national, provincial, and local policies, legislation and institutions that make it possible for the desired decisions to be taken and implemented. The role of the government is crucial. The reasons for governmental involvement are manifold:

- Water is a resource beyond property rights: it cannot be "owned" by private persons. Water rights can be given to persons or companies, but only the rights to use the water and not to own it. Conflicts between users automatically turn up at the table of the final owner of the resource - the government.

- Water is a resource that often requires large investments to develop, treat, store, distribute, 
and use, and then to collect, treat, and dispose or reuse. Examples are multipurpose reservoirs and the construction of dykes along coasts and rivers. The required investments are large and typically can only be made by governments or state-owned companies.

- Water is a medium that can easily transfer external effects. The use of water by one activity often has negative effects on other water using activities (externalities). The obvious example is the discharge of wastewater into a river may save the discharger money but it may have negative effects on downstream users requiring cleaner water.

Only the government can address many of these issues and hence "good governance" is necessary for good water management. An insufficient institutional setting and the lack of a sound economic base are the main causes of water resources development project failure, not technical inadequacy of design and construction. This is also the reason why at present much attention is given to institutional developments and governance in both developed and developing regions and countries.

In Europe, various types of water agencies are operational (e.g., the Agence de l'Eau in France and the water companies in England), each having advantages and disadvantages. The Water Framework Directive of the European Union requires that water management be carried out at the scale of a river basin, particularly when this involves transboundary management. It is very likely that this will result in a shift in responsibilities of the institutions involved and the establishment of new institutions. In other parts of the world experiments are being carried out with various types of river basin organizations, combining local, regional, and sometimes national governments.

\subsubsection{Models for Impact Prediction and Evaluation}

Planning processes have undergone a significant transformation over the past five decades, mainly due to the continuing development of improved computational technology. Planning today is heavily dependent on the use of computer-based impact prediction models. Such models are used to assist in the identification and evaluation of alternative ways of meeting various planning and management objectives. They provide an efficient way of using spatial and temporal data in an effort to predict the interaction and impacts, over space and time, of various river basin components under alternative designs and operating policies.

Many of the systems analysis approaches and models discussed in the following chapters of this book have been, and continue to be, central to the planning and management process. Their usefulness is directly dependent on the quality of the data and models being used. Models can assist planning and management at different levels of detail. Some models are used for preliminary screening of alternative plans and policies, and as such do not require major data collection efforts. Screening models can also be used to estimate how significant certain data and assumptions are to the decisions being considered, and hence can help guide additional data collection activities. At the other end of the planning and management spectrum, much more detailed models can be used for engineering design. These more complex models are more data demanding, and typically require higher levels of expertise for their proper use.

The integration of modeling technology into the social and political components of the planning and management processes in a way that enhances those processes continues to be the main challenge of those who develop planning and management models. Efforts to build and apply interactive generic modeling programs or "shells" into which interested stakeholders can "draw in" their system, enter their data and operating rules at the level of detail desired, simulate it, and discover the effect of alternative assumptions and operating rules, has in many cases helped to create a common or shared understanding among these stakeholders. Getting stakeholders involved in developing and experimenting with their own interactive data-driven models has been an effective way of building a consensus - a shared vision. 


\subsubsection{Models for Shared Vision or Consensus Building}

Participatory planning involves conflict management. Each stakeholder or interest group has its objectives, interests, and agendas. Some of these may be in conflict. The planning and management process is one of negotiation and compromise. This takes time but from it can come decisions that have the best chance of being considered the right decisions by most participants. Models can assist in this process of reaching a common understanding and agreement among different stakeholders. This has a greater chance of happening if the stakeholders themselves are involved in the modeling process.

Involving stakeholders in collaborative model building accomplishes a number of things. It gives them a feeling of ownership. They will have a much better understanding of just what their model can do and what it cannot do. If they are involved in model building, they will know the assumptions built into their model.

Being involved in a modeling exercise is a way to understand better the impacts of various assumptions one must make when developing and running models. While there may be no agreement on the best of various assumptions to make, stakeholders can learn which of those assumptions matter and which do not. In addition, the involvement of stakeholders in the process of model development will create discussions that will lead toward a better understanding of everyone's interests and concerns. Though such model building exercises, it is just possible those involved will reach not only a better understanding of everyone's concerns, but also a common or "shared" vision of at least how their system (as represented by their model, of course) works.

\subsubsection{Models for Adaptive Management}

Recent emphasis has shifted from structural engineering solutions to more nonstructural alternatives, especially for environmental and ecosystem restoration. Part of this shift reflects the desire to keep more options open for future generations. It reflects the desire to be adaptive to new information and to respond to surprisesimpacts not forecasted. As we learn more about how river basins, estuaries, and coastal zones work, and how humans can better manage those resources, we do not want to regret what we have done in the past that may preclude this adaptation.

In some situations, it may be desirable to create a "rolling" plan-one based on the results of an optimization or simulation model of a particular water resource system that can be updated at any time. This permits responses to resource management and regulatory questions when they are asked, not just at times when new planning and management exercises take place. While this appears to be desirable, will planning and management organizations have the financing and support to maintain and update the modeling software used to estimate various impacts, collect and analyze new data, and maintain the expertise, all of which are necessary for continuous planning (rolling plans)?

\subsection{Planning and Management Characteristics}

\subsubsection{Integrated Policies and Development Plans}

Clearly, a portion of any water resources planning and management study report should contain a discussion of the particular site-specific water resource management issues and options. Another part of the report might include a prioritized list of strategies for addressing existing problems and available development or management opportunities in the basin.

Recent emphasis has shifted from structural engineering solutions to more nonstructural alternatives, especially for environmental and ecosystem restoration. Part of this shift reflects the desire to keep more options open for future generations. It reflects the desire to be adaptive to new information and to respond to surprisesimpacts not forecasted. As we learn more about how river basins, estuaries, and coastal zones work, and how humans can better manage their 
water resources, we do not want to be regretting what we have done in the past that may preclude this adaptation.

Consideration also needs to be given to improving the quality of the water resources planning and management review process and focusing on outcomes themselves rather than output measures. One of the outcomes should be an increased understanding of some of the relationships between various human activities and the hydrology and ecology of the basin, estuary, or coastal zone. Models developed for predicting the economic as well as ecologic interactions and impacts due to changes in land and water management and use could be used to address questions such as:

- What are the hydrologic, ecologic, and economic consequences of clustering or dispersing human land uses such as urban and commercial developments and large residential areas? Similarly, what are the consequences of concentrated versus dispersed patterns of reserve lands, stream buffers, and forestland?

- What are the costs and ecological benefits of a conservation strategy based on near-stream measures (e.g., riparian buffers) versus near-source (e.g., upland/site edge) measures? What is the relative cost of forgone upland development versus forgone valley or riparian development? Do costs strongly limit the use of stream buffer zones as mitigating for agriculture, residential, and urban developments?

- Should large intensive developments be best located in upland or valley areas? Does the answer differ depending on economic, environmental, or aquatic ecosystem perspectives? From the same perspectives, is the most efficient and desirable landscape highly fragmented or highly zoned with centers of economic activity?

- To what extent can riparian conservation and enhancement mitigate upland human land use effects? How do the costs of upland controls compare with the costs of riparian mitigation measures?

- What are the economic and environmental quality trade-offs associated with different areas of different classes of land use such as commercial/urban, residential, agriculture, and forest?

- Can adverse effects on hydrology, aquatic ecology, and water quality of urban areas be better mitigated with upstream or downstream management approaches? Can land controls like stream buffers be used at reasonable cost within urban areas, and if so, how effective are they?

- Is there a threshold size for residential/ commercial areas that yield marked ecological effects?

- What are the ecological states at the landscape scale that once attained become irreversible with reasonable mitigation measures? For example, once stream segments in an urban setting become highly altered by direct and indirect effects (e.g., channel bank protection and straightening and urban runoff), can they be restored with feasible changes in urban land use or mitigation measures?

- Mitigating flood risk by minimizing floodplain developments coincides with conservation of aquatic life in streams. What are the economic costs of this type of risk avoidance?

- What are the economic limitations and ecologic benefits of having light residential zones between waterways and commercial, urban, or agriculture lands?

- What are the economic development decisions that are irreversible on the landscape? For example, once land is used for commercial development, it is normally too costly to return it to agricultural land. This would identify limits on planning and management for conservation and development.

- What are the associated ecological and economic impacts of the trend in residential, commercial and forests lands replacing agricultural lands? 
The answers to these and similar questions may well differ in different regions. However, if we can address them on a regional scale, i.e., in multiple river basins, we just might begin to understand and predict better the interactions among economy, environment ecology, and people as a function of how we manage and use its land and water. This in turn may help us better manage and use our land and water resources for the betterment of all —now and on into the future.

\subsubsection{Sustainability}

Sustainable water resource systems are those designed and managed to best serve people living in the future as well as those of us living today. The actions that we as a society take now to satisfy our own needs and desires should not only depend on what those actions will do for us but also on how they will affect our descendants. This consideration of the long-term impacts on future generations of actions taken now is the essence of sustainable development. While the word "sustainability" can mean different things to different people, it always includes a consideration of the welfare of those living in the future. While the debate over a more precise definition of sustainability will continue, and questions over just what it is that should be sustained may remain unanswered, this should not delay progress toward achieving water resource systems that we judge best serves those of us living today as well as our children and their children living in the future.

The concept of environmental and ecological sustainability has largely resulted from a growing concern about the long-run health of our planet. There is increasing evidence that our present resource use and management activities and actions, even at local levels, can significantly affect the welfare of those living within much larger regions in the future. Water resource management problems at a river basin level are rarely purely technical and of interest only to those living within the individual river basins where those problems exist. They are increasingly related to broader societal structures, demands, and goals.

What would future generations like us to do for them? We do not know, but we can guess. As uncertain as these guesses will be, we should take them into account as we act to satisfy our own immediate needs, demands, and desires. There may be trade-offs between what we wish to do for ourselves in our current generation versus what we think future generations might wish us to do for them. These trade-offs, if any, between what present and future generations would like should be considered. Once identified, or at least estimated, just what decisions to make should be debated and decided in the political arena. There is no scientific theory to help us identify which trade-offs, if any, are optimal.

The inclusion of sustainability criteria along with the more common economic, environmental, ecological, and social criteria used to evaluate alternative water resources development and management strategies may identify a need to change how we commonly develop and use our water resources. We need to consider the impacts of change itself. Change over time is certain; just what it will be is uncertain. These changes will impact the physical, biological, and social dimensions of water resource systems. An essential aspect in the planning, design and management of sustainable systems is the anticipation of change. This includes change due to geomorphologic processes, to aging of infrastructure, to shifts in demands or desires of a changing society, and even due to increased variability of water supplies, possibly because of a changing climate. Change is an essential feature of sustainable water resources development and management.

Sustainable water resource systems are those designed and operated in ways that make them more adaptive, robust, and resilient to an uncertain and changing future. Sustainable water resource systems must be capable of effectively functioning under conditions of changing supplies, management objectives, and demands. Sustainable systems, like any others, may fail, but when they fail they must be capable of 
recovering and operating properly without undue costs.

In the face of certain changes, but with uncertain impacts, an evolving and adaptive strategy for water resources development, management, and use is a necessary condition of sustainable development. Conversely, inflexibility in the face of new information and new objectives and new social and political environments is an indication of reduced system sustainability. Adaptive management is a process of adjusting management actions and directions, as appropriate, in light of new information on the current and likely future condition of our total environment and on our progress toward meeting our goals and objectives. Water resources development and management decisions can be viewed as experiments, subject to modificationbut with goals clearly in mind. Adaptive management recognizes the limitations of current knowledge and experience and that we learn by experimenting. It helps us move toward meeting our changing goals over time in the face of this incomplete knowledge and uncertainty. It accepts the fact that there is a continual need to review and revise management approaches because of the changing as well as uncertain nature of our socioeconomic and natural environments.

Changing the social and institutional components of water resource systems are often the most challenging because they involve changing the way individuals think and act. Any process involving change will require that we change our institutions - the rules under which we as a society function. Individuals are primarily responsible for, and adaptive to, changing political and social situations. Sustainability requires that public and private institutions also change over time in ways that are responsive to the needs of individuals and society.

Given the uncertainty of what future generations will want, and the economic, environmental, and ecological problems they will face, a guiding principle for the achievement of sustainable water resource systems is to provide options that allow future generations to alter such systems. One of the best ways to do this is to interfere as little as possible with the proper functioning of natural life cycles within river basins, estuaries, and coastal zones. Throughout the water resource system planning and management process, it is important to identify all the beneficial and adverse ecological, economic, environmental, and social effects - especially the long-term effects-associated with any proposed planning and management project.

\subsection{Meeting the Planning and Management Challenges-A Summary}

Planning (the formulation of development and management plans and policies) is an important and often indispensable means to support and improve operational management. Planning provides an opportunity to:

- assess the current state of the water resources and the conflicts and priorities over their use, formulate visions, set goals and targets, and thus orient operational management,

- provide a framework for organizing policy relevant research and public participation,

- increase the legitimacy, public acceptance of, or even support for how the resources are to be allocated or controlled, especially in times of stress, and

- facilitate the interaction, discussion, and coordination among managers and stakeholders, and generate a common point of reference - a management plan or policy.

Many of the concerns and issues being addressed by water resources planners and managers today are similar to those faced by planners and managers in the past. But some are different. Most of the new ones are the result of two trends: (1) a growing concern for the sustainability of natural ecosystems and (2) an increased recognition for the need of the bottom-up "grassroots" participatory approach to planning, managing, and decision-making.

Today planners work for economic development and prosperity as they did in the past, keeping in mind environmental impacts and 
goals as they have done in the past, but now recognizing ecological impacts and values as well. Water resources management may still be focused on controlling and mitigating the adverse impacts of floods and droughts and water pollution, on producing hydropower, on developing irrigation, on controlling erosion and sediment, and on promoting navigation, but only as these and similar activities are compatible with healthy ecosystems. Natural ecosystems generally benefit from the variability of natural hydrologic regimes. Other users prefer less variability. Much of our engineering infrastructure is operated so as to reduce hydrologic variability. Today water resource systems are increasing, required to provide rather than reduce hydrologic (and accompanying sediment load) variability. Reservoir operators, for example, can modify their water release policies to increase this variability. Farmers and land use developers must minimize rather than encourage land-disturbing activities. Floodplains may need to get wet occasionally. Rivers and streams may need to meander and fish species requiring habitats along the full length of rivers to complete their life cycles must have access to those habitats. Clearly these ecological objectives, added to all the other economic and environmental ones, can only compound the conflicts and issues with respect to land and water management and use.

So, how can we manage all this conflict and uncertainty? We know that water resources planning and management should be founded on sound science, efficient public program administration, and broad participation of stakeholders. Yet obtaining each of these three conditions is a difficult challenge. While the natural and social sciences can help us predict the economic, environmental, and ecological impacts of alternative decisions, those predictions are never certain. In addition, these sciences offer no help in determining the best decision to make in the face of multiple conflicting goals held by multiple stakeholders-goals that have changed, and no doubt will continue to change. Water resources planning and management and decision-making are not as easy as "we professionals can tell you what to do. All you need is the will to do it." Very often it is not clear what should be done. Professionals administering the science, often from public agencies, nongovernmental organizations, or even from universities, are merely among all the stakeholders having an interest in and contributing to the management of water.

Each governmental agency, consulting firm, environmental interest group, and citizen typically has its own limitations, authorities, expertise and conflicts with other people, agencies and organizations, all tending to detract from achieving a fully integrated approach to water resources planning and management. But just because of this, the participation and contributions of all these stakeholders are needed. They must come together in a partnership if indeed an integrated approach to water resources planning and management is to be achieved and sustained. All views must be heard, considered, and acted upon by all involved in the water resources planning and management process.

Water resources planning and management is not simply the application and implementation of science. It is creating a social environment that gets all of us who should be involved, from the beginning, in a continuing planning process. This process is one of

- educating ourselves about how our systems work and function,

- identifying existing or potential options and opportunities for enhancement and resource development and use,

- resolving the inevitable problems and conflicts that will result over who gets what and when and who pays who for what and when,

- making and implementing decisions, and finally of

- monitoring the impacts of those decisions.

This process is repeated as surprises or new opportunities or new knowledge dictates.

Successful water resources planning and management requires the active participation of all community institutions involved in economic development and resource management. How can this begin at the local stakeholder level? How does anyone get others interested in preventing 
problems before those problems are apparent, or especially before "unacceptable" solutions are offered to deal with them? And how do you deal with the inevitable group or groups of stakeholders who see it in their best interest not to participate in the planning process, but to just criticize it from the outside? Who is in a position at the local level to provide that leadership and needed financial support? In some regions, nongovernmental institutions have been instrumental in initiating and coordinating this process at local grassroot levels.

Water resources planning and management processes should identify a vision that guides development and operational activities in the affected region. Planning and management processes should

- recognize and address the goals and expectations of the region's stakeholders,

- identify and respond to the region's water-related problems,

- function effectively within the region's legal/institutional frameworks,

- accommodate both short- and long-term issues,

- generate a diverse menu of alternatives,

- integrate the biotic and abiotic parts of the basin,

- take into account the allocation of water for all needs, including those of natural systems,

- be stakeholder-driven,

- take a global perspective,

- be flexible and adaptable,

- drive regulatory processes, not be driven by them,

- be the basis for policy making,

- foster coordination among planning partners and consistency among related plans,

- be accommodating of multiple objectives,

- be a synthesizer, recognize and deal with conflicts, and

- produce recommendations that can be implemented.

All too often integrated planning processes are hampered by the separation of planning, management and implementing authorities, turf-protection attitudes, shortsighted focusing of efforts, lack of objectivity on the part of planners, and inadequate funding. These deficiencies need addressing if integrated holistic planning and management is to be more than just something to write about.

Effective water resources planning and management is a challenge today, and will be an increasing challenge into the foreseeable future. This book introduces some of the tools that are being used to meet these challenges. We consider it only a first step toward becoming an accomplished planner or manager.

\section{References}

ADB (Asia Development Bank). (2016). Asian Water Development Outlook, Strengthening Water Security in Asia and the Pacific. Mandaluyong City, Philippines.

ASCE (American Society of Civil Engineers). (1998). Sustainability criteria for water resource systems. Reston, VA: ASCE.

Gulbenkian Think Tank (GTT). (2014). Water and the future of humanity. Revaluating Water Security, Calouste Gulbenkian Foundation, New York: Springer. ISBN: 978-3-319-01456-2. doi:10.1007/ 978-3-319-01457-9_1

GWP (Global Water Partnership). (2000). Integrated water resources management. TAC Background Papers No. 4. Stockholm, Sweden: GWP.

IPPC. (2007). Report of the intergovernmental panel on climate change, May.

NRC (National Research Council). (2001). Compensating for wetland losses under the clean water act. Committee on Mitigating Wetland Losses, Board on Environmental Studies and Toxicology, Water Science and Technology Board.

Orr, S., Pittock, J., Chapagain, A., \& Dumaresq, D. (2012). Dams on the Mekong River: Lost fish protein and the implications for land and water resources, Global Environmental Change, 22, 925-932.

UN-Water. (2013). UN-water analytical brief on water security and the global water agenda.

van Beek, E., \& Arriens, W. L. (2014). Water security, putting the concept into practise. TEC Background Paper No. 20. Stockholm: GWP.

Winemiller, K. O., McIntyre, P. B. , Castello, L., Fluet-Chouinard, E., Giarrizzo, T., Nam, S., et al. (2016). Balancing hydropower and biodiversity in the Amazon, Congo, and Mekong Basin-scale planning is needed to minimize impacts in mega-diverse rivers. In Insights perspectives (Vol. 351 Issue 6269 p. 129). AAAS Science. sciencemag.org. January 8, 2016. 


\section{Additional References (Further Reading)}

Abdullah, A., Masih, I.,Van Der Zaag, P., Karim, U. F.A., Popescu, I., Suhail, Q. A. (2015). Shatt al Arab River system under escalating pressure: A preliminary exploration of the issues and options for mitigation. International Journal of River Basin Management, 13(2), 215-227.

Abu-Zeid, M. A., \& Biswas, A. K. (Eds.). (1996). River basin planning and management. Calcutta: Oxford University Press.

American Society of Civil Engineers (ASCE). (1998). Sustainability criteria for water resource systems. Reston, VA: ASCE Press.

American Society of Civil Engineers (ASCE). (2011). Toward a sustainable water future: Visions for 2050. Reston, VA, USA: ASCE Press.

Barrow, C. J. (1998). River basin development planning and management: A critical review. World-Development, Oxford, United Kingdom, 26(1), 171-186.

Bateman, B., \& Rancier, R. (Eds.). (2012). Case studies in integrated water resources management: From local stewardship to national vision. American Water Resources Association Policy Committee, 4 West Federal Street, P.O. Box 1626, Middleburg, Virginia 20118-1626, 60 pp.

Bates, B. C., Kundzewicz, Z. W., Wu, S., \& Palutikof, J. P. (2008). Climate change and water. IPCC Technical Paper VI. Geneva, Switzerland: Intergovernmental Panel on Climate Change.

Biswas, A. K. (Ed.). (1997). Water resources: Environmental planning, management, and development (738 pp). New York, NY: McGraw-Hill.

Cai, X., Vogel, R., \& Ranjithan, R. (Eds.). (2013). Role of systems analysis in watershed management. Journal of Water Resources Planning and Management, 139(5), 461-592.

Chartres, C., \& Varma, S. (2010). Out of water: From abundance to scarcity and how to solve the world's water problems. Upper Saddle River, NJ, USA: Pearson Education Inc.

Cooper, A. B., \& Bottcher, A. B. (1993). Basin-scale modeling as a tool for water-resource planning. Journal of Water Resources Planning and Management (ASCE), 119(3), 306-323. May/June 6 fig, 4 tab, 41 ref.

Priscoli, J. D. (2004). What is public participation in water resources management and why is it important? Water International, 29(2).

Diamantini, C., \& Zanon, B. (1996). River basin planning in Italy: Resource and risk management. EuropeanEnvironment (United Kingdom), 6(4), 119-125.

Eckstein, O. (1958). Water resource development: The economics of project evaluation. Cambridge, MA: Harvard University Press.

Frederick, K. D., Major, D. C., \& Stakhiv, E. Z. (1997). Water resources planning principles and evaluation criteria for climate change: Summary and conclusions. Climate Change, 37(1), 291-313.
Gershon, M., \& Duckstein, L. (1983). Multiobjective approaches to river basin planning. Journal-WaterResources-Planning-Management-Division, American Society of Civil Engineers USA), 109(1), 13-28.

Gleick, P. H. (2002). Soft water paths. Nature, 418, 373.

Gleick, P. H. (2003). Water use. Annual Review of Environment and Resources, 28, 275-314.

Gleick, P. H., \& Palaniappan, M. (2010). Peak water: Conceptual and practical limits to freshwater withdrawal and use. Proceedings of the National Academy of Sciences of the United States of America, 107(25), 11155-11162.

Global Water Partnership (GWP). (2000). Water as a social and economic good: How to put the principle into practice. TAC Background Papers No. 2. Stockholm, Sweden: GWP.

Global Water Partnership (GWP). (2000). Effective water governance. TAC Background Papers No. 7. Stockholm, Sweden: GWP.

Global Water Partnership (GWP). (2012). The handbook for integrated water resources management in transboundary basins of rivers, lakes and aquifers (120 pp). International Office for Water (Permanent Technical Secretariat of the International Network of Basin Organizations). ISBN: 978-91-85321-85-8.

Goulter, I. C. (1985). Equity issues in the implementation of river basin planning. Strategies for river basin management: Environmental integration of land and water in a river basin (pp. 287-292, 15 refs.). Dordrecht, Holland: D. Reidel Publishing Co.

Gulbenkian Think Tank. (2014). Water and the future of humanity. Revisiting water security (241 pp). New York: Springer. doi:10.1007/978-3-319-01457-9

Haasnoot, M., Kwakkel, J. H., Walker, W. E., \& ter Maat, J. (2013). Dynamic adaptive policy pathways: A method for crafting robust decisions for a deeply uncertain world. Global Environmental Change, 23, 485-498.

Habersack, H., Haspel, D., \& Campbell, I. (Eds.). (2013). Integrated management of large river systems. International Journal of River Basin Management, 11(2), 137-236.

Hoekstra, A. Y., \& Chapagain, A. K. (2008). Globalization of water. Sharing the planet's freshwater resources. Oxford, UK: Blackwell Publishing.

Hoekstra, A. Y., \& Mekonnem, M. M. (2012). The water footprint of humanity. Proceedings of the National Academy of Sciences, Washington DC, 109(9), 3232-3237.

Howe, C. W. (1996). Water resources planning in a federation of states: Equity versus efficiency. Natural Resources Journal, 36(1), 29-36.

Huaicheng, Guo, \& Beanlands, G. (1994). A comparative study on Canadian and Chinese river basin planning. Journal of Environmental Science China, 6(2), 224-233.

IPCC (Intergovernmental Panel on Climate Change). (2001). Climate change 2001: Synthesis report, summary for policymakers. Third Assessment Report, IPCC. 
IPCC (Intergovernmental Panel on Climate Change). (2007). Climate change 2007: The physical science basis. Fourth Assessment Report, IPCC.

IWMI (International Water Management Institute). (2007). Water for food, water for life. A comprehensive assessment of water management in agriculture. London, UK: Earthscan, and Colombo, Sri Lanka: IWMI.

Karamouz, M., Szidarovszky, F., \& Banafsheh, Z. (2003). Water resources systems analysis. Boca Raton, FL: Lewis.

Kulshreshtha, S. (1998). A global outlook for water resources to the year 2025. Water Resources Management, 12(3), 167-184.

Krutilla, J. V., \& Eckstein, O. (1958). Multiple purpose river development. Baltimore, MD: Johns Hopkins Press.

Lee, D. J., \& Dinar, A. (1996). Integrated models of river basin planning, development, and management. Water International, 21(4), 213-222. Also see: (1995). Review of integrated approaches to river basin planning, development and management. World Bank, Agriculture and Natural Resources Department, Washington, DC.

Lins, H. F., Wolock, D. M., \& McCabe, G. J. (1997). Scale and modeling issues in water resources planning. Climate Change, 37(1), 63-88.

Loucks, D. P., Stedinger, J.R., \& Haith, D.A. (1981). Water resources systems planning and analysis (559 pp). Englewood Cliffs, NJ: Prentice-Hall.

Loucks, D. P., \& da Costa, J. R. (Eds.). (1991). Decision support systems: Water resources planning and research. Berlin: Springer.

Loucks, D. P. (Ed.). (1998). Restoration of degraded rivers: Challenges, issues and experiences (484 pp). Dordrecht, NL: Kluwer Academic Publishers.

Maidment, D. R. (Ed.). (1993). Handbook of hydrology. New York, NY: McGraw-Hill.

Maass, A., et al. (1962). Design of water resource systems. Cambridge, MA: Harvard University Press.

Major, D. C., \& Lenton, R. L. (Eds.). (1979). Applied water resource systems planning (248 pp). Englewood Cliffs, NJ: Prentice-Hall, Inc.

Mays, L. W. (Ed.). (1996). Water Resources Handbook. NY, NY: McGraw-Hill.

McMillan, T. (1990). Water resource planning in Canada. Journal of Soil and Water Conservation, 45 (6),614-616.

Mimikou, M. A., Baltas, E. A., \& Tsihrintzis, V. A. (2016). Hydrology and water resource systems analysis (456 pp). CRC Press.

Mitchell, B. (1983). Comprehensive river basin planning in Canada: Problems and opportunities. Water International, 8(4), 146-153.

MRC (Mekong River Commission) Secretariat. (2009). Inception report: MRC SEA for hydropower on the Mekong mainstream. Phnom Penh, Cambodia: MRC and International Center for Environmental Management.

National Research Council (NRC). (2001). Compensating for Wetland Losses Under the Clean Water Act (348 pp). Committee on Mitigating Wetland Losses,
Board on Environmental Studies and Toxicology, Water Science and Technology Board.

Nijhuis, M. (2015). Harnessing the Mekong, or killing it? National Geographic, Journal of National Geographic Society, 227(5), 102-129.

O'Riordan, J. (1981). New strategies for water resource planning in British Columbia. Canadian Water Resources Journal, 6(4), 13-43. 6 Figs, 5 Tabs.

Razavian, D.,Bleed, A. S., Supalla, R. J., \& Gollehon, N. R. (1990). Multistage screening process for river basin planning. Journal of Water Resources Planning and Management (ASCE), 116(3), 323-334. May/June 3 fig, 1 tab, 19 refs, 3 append.

Reitsma, R. F., \& Carron, J. C. (1997). Object-oriented simulation and evaluation of river basin operations. Journal of Geographic Information and Decision Analysis, 1(1), 9-24.

Reynolds, P. J. (1985). Ecosystem approaches to river basin planning strategies for river basin management: Environmental integration of land and water in a river basin (pp. 41-48, 1 fig, 18 refs). Dordrecht, Holland: D. Reidel Publishing Co.

Sadoff, C. W., Hall, J. W., Grey, D., Aerts, J. C. J. H., Ait-Kadi, M., Brown, C., et al. (2015). Securing water, sustaining growth: Report of the GWP/OECD task force on water security and sustainable growth (180 pp). UK: University of Oxford.

Saha, S. K., \& Barrow, C. J. (Eds.). (1981). River basin planning: Theory and practice (357 pp). Chichester, UK: Wiley Interscience.

Savenije, H. H. G., \& van der Zaag, P. (Eds.). (1998). The management of shared river basins (164 pp). The Hague, NL: Ministry of Foreign Affairs, Neda.

Schramm, G. (1980). Integrated river basin planning in a holistic universe. Natural Resources Journal, 20(4), 787-806. 2 Fig, 1 tab, 48 refs.

Smith, S. C., \& Castle, E. N. (Eds.). (1964). Economics and public policy in water resources development. Ames, Iowa: Iowa University Press.

Somlyody, L. (1997). Use of optimization models in river basin water quality planning. In M. B. Beck \& P. Lessard (Eds.), WATERMATEX '97. Systems analysis and computing in water quality management. Towards a new agenda (391 pp).

Stout, G.E. (1998). Sustainable development requires the full cooperation of water users. Water International, 23(1), 3-7.

Thanh, N. C., \& Biswas, A. K. (Eds.). (1990). Environmentally-sound water management (276 pp). Delhi: Oxford University Press.

Thiessen, E. M., Loucks, D. P., \& Stedinger, J. R. (1998). Computer-assisted negotiations of water resources conflicts. Group Decision and Negotiation, 7(2).

Thissen, W. A. H., \& Walker, W. E. (Eds.). (2013). Public policy analysis: New developments (286 pp). New York, Heidelberg, Dordrecht, London: Springer. ISBN: 978-1-4614-4601-9; ISBN: 978-1-4614-4602-6 (eBook). doi:10.1007/978-1-4614-4602-6

Tolley, G. S., \& Riggs, F. E. (Eds.). (1961). Economics of watershed planning. Ames, Iowa: Iowa State University Press. 
UN WWAP (United Nations World Water Assessment Programme). (2009). The United Nations World Water Development Report 3: Water in a changing world. Paris, France: UNESCO and London, UK: Earthscan.

UN WWAP (United Nations World Water Assessment Programme). (2011). World water scenarios to 2050, exploring alternative futures of the world's water and its use to 2050. Paris, France: UNESCO.

UN WWAP (United Nations World Water Assessment Programme). (2012). The United Nations World Water Development Report 4: Managing water under risk and uncertainty. Paris, France: UNESCO.

UNDP (United Nations Development Programme). (2011). Human Development Report. In Sustainability and equity: A better future for all. New York, NY, USA: UNDP.

UNEP (United Nations Environment Programme). (2002). Global environmental outlook 3: Past, present and future perspectives. London, UK: Earthscan and Nairobi, Kenya: UNEP.

UNEP (United Nations Environment Programme). (2006). Marine and coastal ecosystems and human well-being: A synthesis report based on the findings of the millennium ecosystem assessment. Nairobi, Kenya: UNEP.

UNEP (United Nations Environment Programme). (2009). Towards sustainable production and sustainable use of resources: Assessing biofuels. France: UNEP, produced by the International Panel for Sustainable Resource Management, Division of Technology Industry and Economics, France.

Viessman, W. (1996). Integrated water management. Water Resources Update, (106), 2-12).

Viessman, W. (1998). Water policies for the future. Water Resources Update, (111), 4-7, 104-110.

Vörösmarty, C. J., Green, P., Salisbury, J., \& Lammers, R. B. (2000). Global water resources: Vulnerability from climate change and population growth. Science, 289(5477), 284-288.

Vörösmarty, C. J., McIntyre, P. B., Gessner, M. O., Dudgeon, D., Prusevich, A., Green, P., et al. (2010). Global threats to human water security and river biodiversity. Nature, 467, 555-561.

Walker, W. E., Haasnoot, M., \& Kwakkel, J. H. (2013). Adapt or perish: A review of planning approaches for adaptation under deep uncertainty. Sustainability, 5, 955-979.

Watkins, D. W. Jr. (Ed.). (2013). Water resources systems analysis through case studies: Data and models for decision making (168 pp). Reston, VA: ASCE Press.

WCD. (2000). Dams and developments - A new framework for decision-making: The report of the World Commission on Dams. UK: Earthscan.

White, G. F. et al. (1999). Water for the future: The West Bank and Gaza Strip, Israel, and Jordan. Water Science and Technology Board and the Board on Environmental Studies and Toxicology, National Research Council, National Academy Press, Washington, DC.

Wong, E. (2013). Pollution rising, Chinese fear for soil and food. NY Times. December 31, 2013.
Wood, A. W., Lettenmaier, D. P., \& Palmer, R. N. (1997). Assessing climate change implications for water resources planning. Climate Change, 37(1), 203-228.

Wright, W. C., Cohen, R., \& Heath, J. H. (1982). Decentralizing water resource planning and management. Journal of the American Water Works Association, 74(7), 6, 334-345. July, 5 Fig, 2 Tab, 37 Ref.

WWAP, (United Nations World Water Assessment Programme). (2012). World water development report 4, 2012. Managing water under uncertainty and risk (867 pp). Paris: UNESCO.

WWAP (United Nations World Water Assessment Programme). (2015). World water development report 2015. Water for a sustainable world (224 pp; Case studies, 61 pp). Paris: UNESCO.

WWAP (United Nations World Water Assessment Programme). (2014). The United Nations world water development report 2014: Water and energy (133 pp). Paris: UNESCO.

Xie, J., Liebenthal, A., Warford, J. J., et al. (2009). Addressing China's water scarcity: Recommendations for selected water resource management issues. Washington, DC, USA: World Bank.

Zhang, R., Zhou, J., Zhang, H., Liao, X., \& Wang, X. (2014). Optimal operation of large-scale cascaded hydropower systems in the Upper Reaches of the Yangtze River, China. Journal of Water Resources Planning and Management, 140(4), 480-495.

\section{Exercises}

1.1 How would you define "Integrated Water Resources Management" and what distinguishes it from "Sustainable Water Resources Management"?

1.2 Can you identify some common water management issues that are found in many parts of the world?

1.3 Comment on the common practice of governments giving aid to those in drought or flood areas without any incentives to alter land use management practices in anticipation of the next drought or flood.

1.4 What tools and information are available for developing integrated water resources plans and management policies?

1.5 What structural and nonstructural measures can be taken to address water resources issues?

1.6 Find the following statistics:

- Percent of all freshwater resources worldwide available for drinking; 
- Number of people who die each year from diseases associated with unsafe drinking water;

- Percent of total freshwater resources in polar regions;

- Per capita annual withdrawal of cubic meters of freshwater in various countries;

- Average world per capita annual withdrawal of cubic meters of freshwater;

- Tons of pollutants entering lakes and rivers daily in various regions;

- Average number of gallons of water consumed by humans in a lifetime;

- Average number of kilometers per day a woman in a developing country must walk to fetch fresh water.

1.7 Identify and briefly describe the six greatest rivers in the world.

1.8. Identify some of the major water resource management issues in the region where you live. What management alternatives might effectively reduce some of the problems or provide additional economic, environmental, or social benefits.

1.9. Describe some water resource systems consisting of various interdependent natural, physical, and social components. What are the inputs to the systems and what are their outputs? How did you decide what to include in the system and what not to include?

1.10. Sustainability is a concept applied to renewable resource management. In your words define what that means and how it can be used in a changing and uncertain environment both with respect to water supplies and demands. Over what space and timescales is it applicable, and how can one decide whether or not some plan or management policy will be sustainable? How does this concept relate to the adaptive management concept?

1.11. Identify and discuss briefly some of the major issues and challenges facing water managers today.
Open Access This chapter is distributed under the terms of the Creative Commons Attribution-NonCommercial 4.0 International License (http://creativecommons.org/ licenses/by-nc/4.0/), which permits any noncommercial use, duplication, adaptation, distribution and reproduction in any medium or format, as long as you give appropriate credit to the original author(s) and the source, provide a link to the Creative Commons license and indicate if changes were made.
The images or other third party material in this chapter are included in the work's Creative Commons license, unless indicated otherwise in the credit line; if such material is not included in the work's Creative Commons license and the respective action is not permitted by statutory regulation, users will need to obtain permission from the license holder to duplicate, adapt or reproduce the material. 